\title{
2010
}

\section{Natural Gas in India}

International Energy Agency

Anne-Sophie Corbeau

WORKING PAPER 
The International Energy Agency (IEA), an autonomous agency, was established in November 1974. Its mandate is two-fold: to promote energy security amongst its member countries through collective response to physical disruptions in oil supply and to advise member countries on sound energy policy.

The IEA carries out a comprehensive programme of energy co-operation among 28 advanced economies, each of which is obliged to hold oil stocks equivalent to 90 days of its net imports. The Agency aims to:

- Secure member countries' access to reliable and ample supplies of all forms of energy; in particular, through maintaining effective emergency response capabilities in case of oil supply disruptions.

- Promote sustainable energy policies that spur economic growth and environmental protection in a global context - particularly in terms of reducing greenhouse-gas emissions that contribute to climate change.

- Improve transparency of international markets through collection and analysis of energy data.

- Support global collaboration on energy technology to secure future energy supplies and mitigate their environmental impact, including through improved energy

efficiency and development and deployment of low-carbon technologies.

- Find solutions to global energy challenges through engagement and dialogue with non-member countries, industry, international organisations and other stakeholders.

IEA member countries:

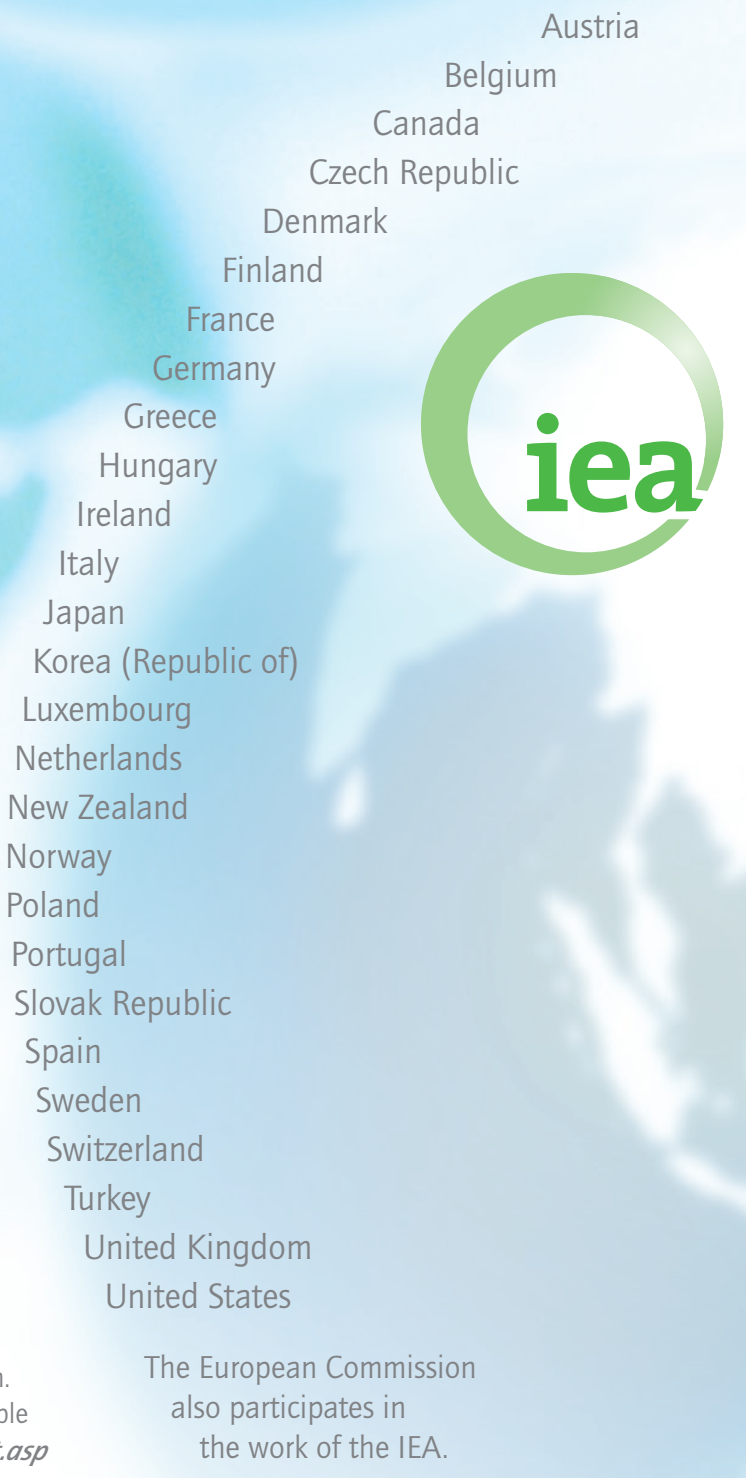

\section{(c) OECD/IEA, 2010 \\ International Energy Agency \\ 9 rue de la Fédération \\ 75739 Paris Cedex 15, France}

Please note that this publication is subject to specific restrictions that limit its use and distribution. The terms and conditions are available online at www.iea.org/about/copyright.asp
International Energy Agency

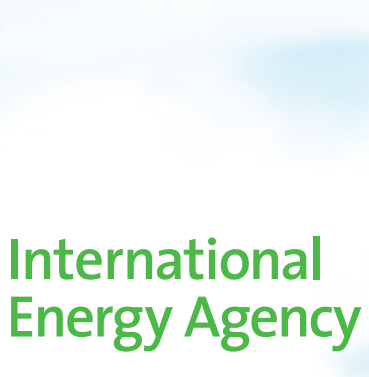




\section{Natural Gas} in India

The views expressed in this working paper are those of the author(s) and do not necessarily reflect the views or policy of the International Energy Agency (IEA) Secretariat or of its individual member countries. This paper is a work in progress, designed to elicit comments and further debate; thus, comments are welcome, directed to the author at:

International Energy Agency

Anne-Sophie Corbeau

WORKING PAPER 


\section{Acknowledgements}

This Working Paper aims to provide a detailed yet non-exhaustive overview of the Indian gas market, highlighting the current challenges (as of mid-2010). The author would like to thank all the contributors and reviewers for their input and comments: Sara Piskor for her outstanding research on the Indian gas market, which gave birth to this Woking Paper; Dagmar Graczyk for her precious and insightful comments; and Didier Houssin, lan Cronshaw, Brian Ricketts, Sun Joo Ahn and Hiroshi Hashimoto for their careful reviews. This paper also draws on more general research performed at the IEA, notably by Michiel Nijboer on natural gas vehicles, as well as on energy statistics. A special thank you goes to Anne Mayne and Delphine Grandrieux for designing the template, Corinne Hayworth for the cover and Janine Treves for her edits. 


\section{Table of contents}

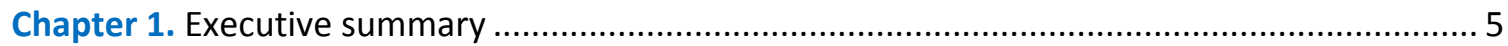

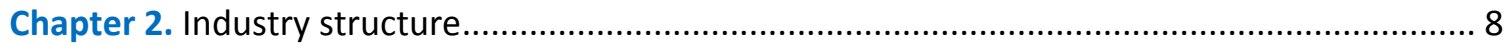

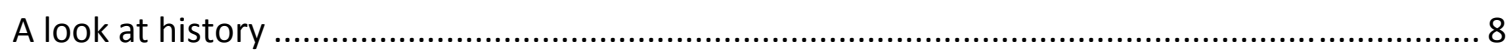

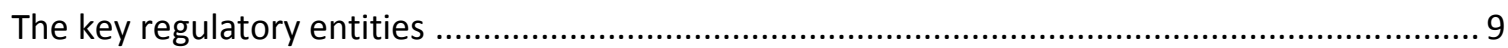

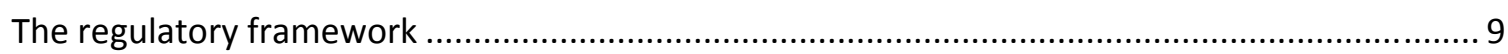

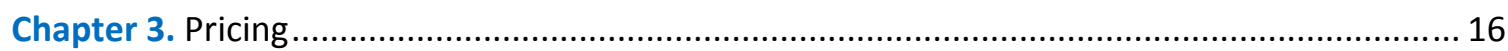

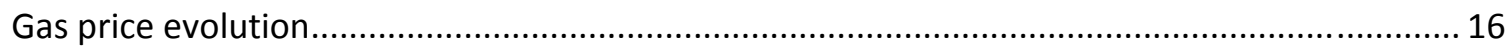

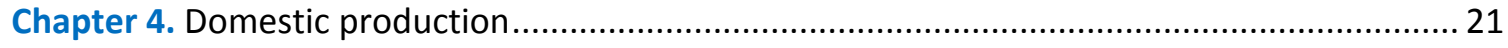

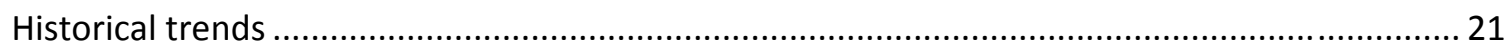

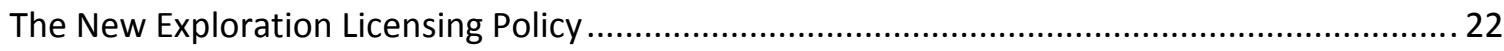

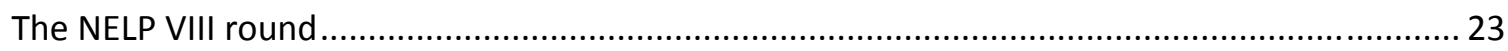

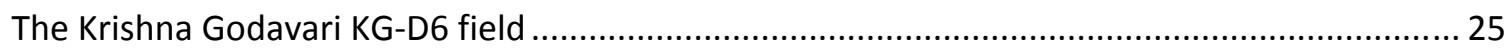

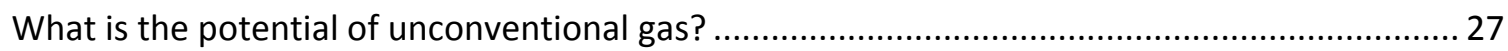

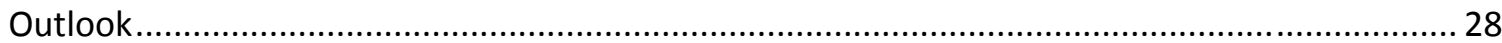

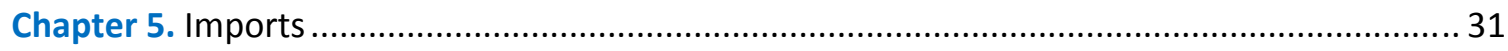

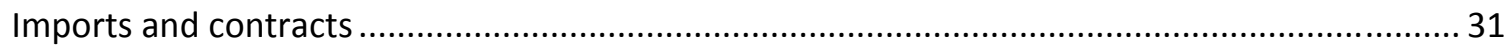

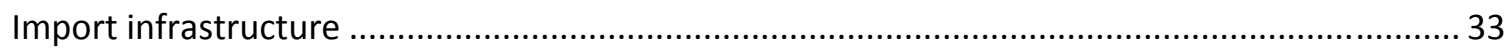

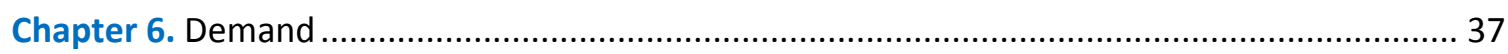

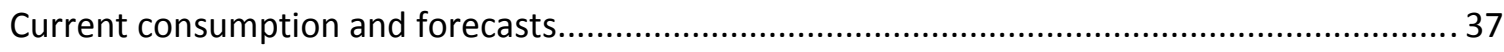

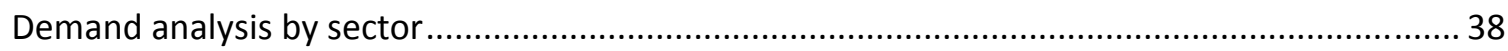

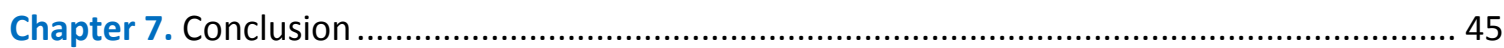

Acronyms

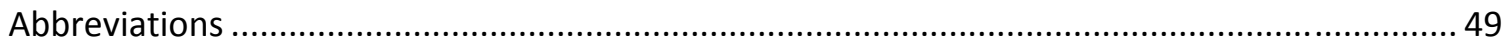

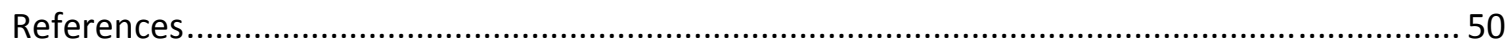

\section{Figures, tables and maps}

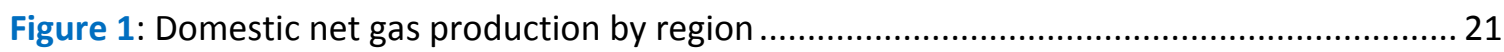

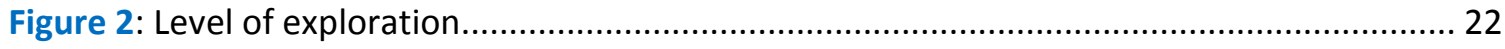

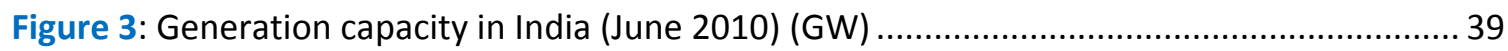

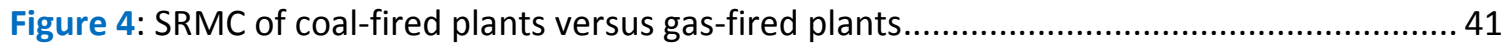

Figure 5: Generating costs of coal-fired plants versus gas-fired plants ....................................... 42 


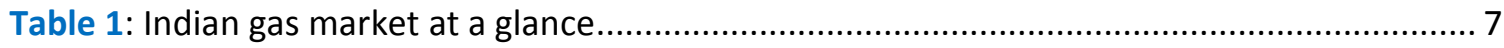

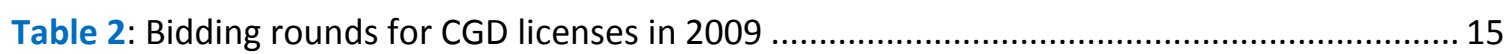

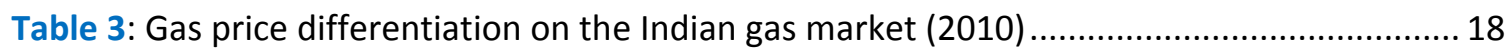

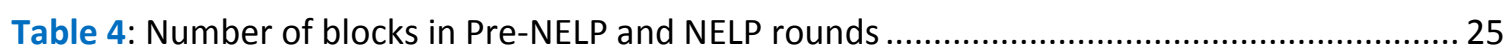

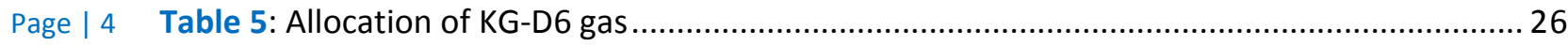

Table 6: Domestic gas supply outlook - Projection by the working group of XI Five-Year

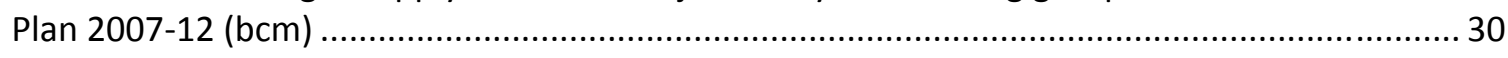

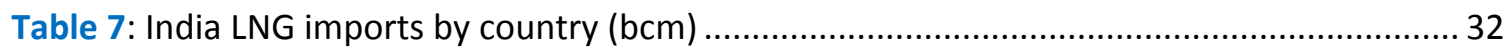

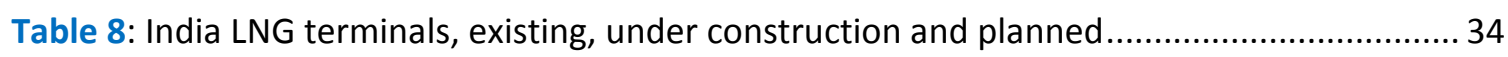

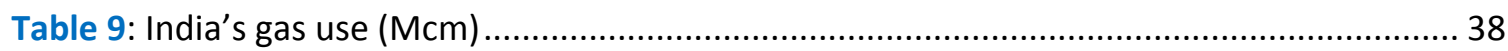

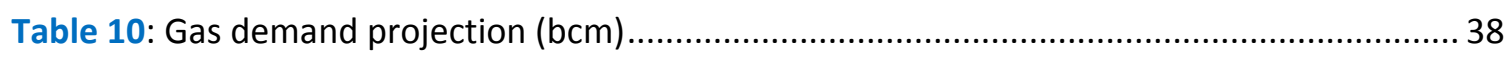

Map 1: Existing and proposed gas pipelines in India ..................................................... 14 


\section{Executive summary}

The Indian gas market is expected to be one of the fastest growing in the world over the next two decades: the IEA forecasts gas demand to increase at 5.4\% per annum over 2007-30 (IEA, 2009) reaching $132 \mathrm{bcm}$ by 2030 . Indian primary energy supply is currently dominated by coal $(37 \%)$, biomass and waste $(27 \%)$ and oil $(26 \%)$ while the share of natural gas is only $6 \%$. Natural gas use in India really started to grow in the late 1970s after the first major gas finds in the western offshore and the development of the first transmission pipeline in the northern region. Before 2009, gas demand potential was estimated to be 20 or $30 \mathrm{bcm}$ higher than actual use as consumption had been constrained by the lack of supply for over a decade (MoPNG, 2000). To address the supply shortfall, the Indian government passed some reforms at the end of the 1990s to encourage domestic production and the construction of liquefied natural gas (LNG) terminals. In particular, the New Exploration Licensing Policy (NELP) opened Exploration \& Production to private and foreign companies. This has been relatively successful: after stagnating since the early 2000s, Indian gas production is expected to double between 2008 and 2011 due to the start of the Krishna Godavari KG-D6 field in April 2009.

The year 2009 therefore marks a turning point for the Indian gas market: with new supplies available, Indian gas consumption increased to $59 \mathrm{bcm}$ in $\mathrm{FY} 2009 / 10$, from $43 \mathrm{bcm}$ in FY 2008/09. ${ }^{1}$ Meanwhile a third LNG terminal is expected to start in 2010. But challenges remain, illustrated by NELP's failure to attract the major international oil companies and the long battle over the allocation and price of KG-D6 gas. The government is now considering introducing an Open Acreage Licensing Policy (OALP).

The potential for growth of the natural gas market in India is tremendous; however, this is a very price sensitive market as the ability of customers to pay differs between sectors. The power generation and fertiliser sectors are the main consumers. Fertiliser producers are subsidised by the government and have limited ability to absorb higher prices. In the power generation sector, gas has to compete against coal for base-load generation. Any change in the power sector or in coal markets will have a huge impact on whether gas is used as a base-load option or for peak purposes, and therefore on future gas demand in the power sector. City gas and industrial users show greater price flexibility, but they are still emerging markets. Historically, gas had been allocated in priority to fertiliser and power plants, while city gas, compressed natural gas (CNG) and industrial had the remainder. Furthermore, fertiliser producers and power generators were allocated gas at low Administrative Price Mechanism (APM) prices determined by the government. But the recent pricing reforms that took place mid2010 mean the end of low APM prices, and that new gas supplies are likely to be more expensive.

The Indian gas sector, like the whole energy sector, is dominated by state-owned companies. Oil and Natural Gas Corporation (ONGC) and Oil India Ltd (OIL) have dominant upstream positions, while until 2006, Gas Authority of India Ltd (GAIL) alone had been responsible for pipeline gas transport. The state has also a very important role in the regulatory framework and gas policy, in particular the allocation and pricing of gas. Recent reforms have brought more private investors in the upstream and downstream sectors, but a more transparent regulatory framework will be critical to incentivise future private investments.

The Indian gas market is therefore at a crossroads in 2010. Despite the dramatic increase of domestic production, last year has witnessed a tough battle over the allocation and the pricing of KG-D6 gas, which could have far-reaching consequences for many stakeholders. In order for

1 Ministry of Petroleum and Natural Gas. These data refer to the Indian fiscal year (1 April, 31 March). 
the Indian gas market to reach its potential, there are still many hurdles to be solved on pricing, supply, infrastructure, regulation and policy.

- Gas pricing. India has a rather unusual dual gas pricing and supply policy, with APM gas produced by state-owned companies and non-APM gas from private companies and joint ventures (JVs). Until May 2010, prices differed widely from around USD 2/MBtu for APM gas to almost USD 6/MBtu for the most expensive non-APM gas. Such a gap was pushing towards changes. Increasing private supply of gas has been indeed a major policy challenge for the government as the pooling of gas prices was limited by the declining availability of APM gas. Moreover, any effort to keep domestic gas prices low would act as a disincentive for more upstream investment.

Two major changes took place in May 2010. APM prices were increased from USD 1.8/MBtu to USD 4.2 MBtu, and ONGC and OIL were allowed to market gas discovered in new fields allocated to them at market prices. This decision will have consequences for producers, and is an important step forward in order to encourage further investments in the upstream sector. Furthermore, if India wants to attract additional LNG in the long term, it would have increasingly to compete on global gas markets at prices potentially higher than the current ones. Meanwhile, the Supreme Court announced its verdict on the five-year battle between Reliance Industry (RIL) and Reliance Natural Resources (RNRL) regarding the price at which RIL was to sell its KG-D6 gas to RNRL: the Court decided that only the government had the right to fix the price in the Production Sharing Contract (PSC) (fixed at USD 4.2/MBtu) when an arm-lengths price is impossible to find. It remains to be seen whether or not such a decision could deter private or foreign upstream investment.

Pricing is also key for the demand side due to some sectors' limited ability to absorb high prices: gas-fired plants compete with coal-fired plants while fertiliser producers depend on international urea price and government subsidies. A market approach based on comparison with alternative fuels should be taken.

- Insufficient supplies. The bulk of India's supplies is produced domestically but demand for gas is increasing while production from the old fields has been dwindling. While most gas production used to be produced by state-owned companies, this is changing rapidly: JVs and private companies represent an increasing share of domestic production. Although domestic production will double between 2008 and 2012, developing domestic gas resources is critical to increase supplies to the Indian market. Even if NELP has resulted in a certain number of discoveries, including the major Krishna Godavari KG-D6 field, it also has some shortcomings. India is also likely to see imports increasing over the next two decades. Although India is also located near significant resources of gas in Turkmenistan and Iran, pipeline interconnections remain a distant prospect. India has been turning to LNG instead and is building new regasification terminals, adding to existing capacity. Future supplies in the coming five years will therefore continue to be based on two sources: domestic production and LNG imports.

- Regulation and policy. The challenges faced by the Indian energy sector and by the gas sector in particular are tremendous. Insufficient supplies remain a policy issue despite a relative improvement. Meanwhile, the downstream gas market is quite underdeveloped so that significant investments will be needed in order to give access to gas to more consumers. This implies attracting investments from both public and private companies; private companies will require a stable and transparent regulatory framework and an equal treatment compared to state-owned companies. The Petroleum and Natural Gas Regulatory Board (PNGRB) Act, 2006 is a step in the right direction but needs to be further enhanced. 
The recent decision of the Delhi High Court, in early 2010, puts PNGRB's role in question and casts new uncertainties on the regulation of downstream gas markets.

- Transmission/infrastructure. India is a vast country and the pipeline network has been developed mostly in the northwest region. In 2008, a pipeline was built to link a new production region in the East to the existing network. In order to further develop the use of gas, it is critical to extend the transmission infrastructure to supply new cities and develop distribution networks. In both cases, the regulatory framework, in particular transport tariffs, should give adequate incentives for the new infrastructure to be built.

This IEA Working Paper aims to provide a detailed yet non-exhaustive overview of the Indian gas market, highlighting the current challenges. It first looks at the industry structure, presents the main players from industry as well as government, and gives an overview of the regulatory framework. The issue of pricing remains crucial for both upstream and downstream development. For this reason, this Working Paper analyses both supply - domestic production and LNG imports - and demand.

Table 1: Indian gas market at a glance

\begin{tabular}{l|cccc}
\hline & $\mathbf{1 9 9 0}$ & $\mathbf{2 0 0 0}$ & $\mathbf{2 0 0 8}$ & $\mathbf{2 0 0 9}$ \\
\hline Share in TPES (\%) & 3 & 5 & 6 & $\mathrm{Na}$ \\
Domestic production $(\mathrm{bcm})$ & 12 & 28 & 32 & 46 \\
LNG imports (bcm) & 0 & 0 & 11 & 12 \\
Pipeline imports (bcm) & 0 & 0 & 0 & 0 \\
Consumption (bcm) & 12 & 28 & 42 & 59 \\
\% of power generation & 37 & 44 & 40 & $\mathrm{Na}$ \\
\% of industry & 59 & 44 & 47 & $\mathrm{Na}$ \\
\hline
\end{tabular}

Source: IEA statistics, Ministry of Petroleum and Natural Gas. 


\section{Industry structure}

To understand the Indian gas market and its current issues, it is necessary to have a look back at the historical development of the energy industry, and in particular the gas industry, and see how gas market players were created or entered the market. It is also crucial to understand how the regulatory framework was set up and the interactions between the government and the industry.

Like in many markets, the Indian energy (and gas) industry has been built on state-owned companies such as ONGC, OIL and GAIL, but has seen the entrance of some significant private companies in the past few years. Some players are present at many levels of the gas value chain. The conditions for private companies to operate in the Indian market are difficult, due to government interventions on gas prices and allocation, the existence of a dual pricing system and the lack of a transparent, predictable and stable regulatory framework.

\section{A look at history}

Exploration and production (E\&P) in India began in the $19^{\text {th }}$ century. In 1866 , the first well was drilled and the first commercial discovery was made in 1889 in Digboi. E\&P activities were thereafter mainly limited to the Assam Oil Company and Attock Oil.

The development of the oil and gas industry really started after the independence of India in the 1950s and 1960s. In 1948, the Government of India (Gol) enacted the Industrial Policy Statement calling for the development of the petroleum industry in India. Until 1955, private companies such as the Burmah Oil Company/Assam Oil Company (BOC/AOC) conducted exploration work, but most of India, in particular offshore, remained unexplored. In 1955, Gol decided to develop oil and gas resources, creating an Oil and Natural Gas Directorate (ONGD), dependent upon the then Ministry of Natural Resources and Scientific Research. In 1956, the Gol adopted the Industrial Policy Resolution placing the development of the oil industry under the responsibility of the state, transforming the Directorate into a commission (ONGC), whose authority was progressively enhanced over the following years. OIL India Private Ltd was created in 1959, with two thirds owned by BOC/AOC and the rest by Gol. It became a Joint Venture (JV) in 1961 with equal ownership between BOC/AOC and Gol. Gas production by OIL began in 1959 in Assam, followed by the ONGC in Gujarat in 1964.

Gas demand was very low until the 1970s but started to pick up when ONGC's Bombay High started producing in 1974 . In 1981, OIL became a wholly state-owned company. With the growth of gas production, it became necessary to develop the downstream part of the gas value chain. In 1984, state-owned GAIL was created to promote gas use and develop midstream and downstream gas infrastructure.

In 1991, India entered into a liberalisation process for the economy, and began to deregulate the gas market and disengage itself from Public Service Undertakings (PSU). The Directorate General of Hydrocarbons (DGH) was created in 1993 to oversee the upstream sector. In 1994, ONGC was reorganised as a public company and Gol divested $2 \%$ of its share through competitive bidding. In 1999, $10 \%$ was sold to India Oil Corporation (IOC) and $2.5 \%$ to GAIL. In 1997, Gol started to open the upstream sector to private and foreign investments through the NELP by allowing them 100\% project ownership. Between 1997 and 2009, eight licensing rounds took place (see sections on NELP in the domestic production section for more details). Meanwhile, GAIL started to build a transmission network with the first major transregional pipeline, the Hazira-Vijaipur-Jagdishpur (HVJ) completed in 1991, and gas distribution in major cities progressively took place over the following decade. A few private players and foreign 
companies have entered the Indian gas market in different parts of the gas value chain (upstream, transmission, LNG terminals, and distribution). RIL, active in upstream, transmission and distribution, is the most notorious example.

\section{The key regulatory entities}

Gol plays a key role in different energy sectors through dedicated ministries. A total of five ministries or departments oversee the energy sector: the Ministry of Power, the Ministry of Coal, the Ministry of Petroleum and Natural Gas, the Ministry of New and Renewable Energy and the Department of Atomic Energy. Two regulators now exist for the upstream and downstream oil and gas sectors. The main players for the gas industry are therefore the following:

- The Ministry of Petroleum and Natural Gas (MoPNG) oversees the exploration and production of oil and natural gas; their refining, distribution and marketing; and the import, export and conservation of petroleum, products and liquefied natural gas. It has been regulating the allocation and pricing of gas produced by ONGC and OIL through administrative orders while the gas from JVs and NELP is governed by Production Sharing Contracts (PSC). A total of 14 Public Service Undertakings (PSU) such as GAIL, and ONGC, depend on the ministry as well as 8 entities such as the Petroleum Planning and Analysis Cell (PPAC) and the Directorate General for Hydrocarbons.

- The Directorate General for Hydrocarbons (DGH) was established in 1993 and can be considered as the upstream regulator. It has responsibilities of promoting the NELP and new exploration programmes, and managing the PSCs.

- The Petroleum and Natural Gas Regulatory Board (PNGRB) was created in 2006 to oversee the downstream part of the market. The members of the Board are nominated by the government. The Board is independent from the Ministry, but Gol can occasionally give the Board directions in the interest of sovereignty and to maintain or increase supplies. Its mission involves protecting the interests of consumers, but also registering and authorising companies active in LNG, storage, city distribution and transport. It also regulates transportation access and rates, and access to distribution or city networks. The role of PNGRB in giving licenses for city gas distribution has been challenged and the Delhi High Court ruled early 2010 that PNGRB did not have the authority to issue such licences. The notification of Section 16 of the PNGRB Act by the government, which was issued on 15 July, empowered the downstream oil regulator to issue authorisations for CGD licences.

\section{The regulatory framework}

\section{Allocation and pricing of upstream gas}

Natural gas is a scarce resource in India and Gol plays an important role in its allocation. Historically, gas has been allocated in priority to end-users such as fertiliser producers and power plants. In 2007, the Gol started working on a new Gas Utilisation Policy. This was mostly a consequence of the dispute between the Ambani brothers (see further in the Domestic Production section) and the related issues on gas pricing and utilisation, which created a very hot debate in India. This and the large gap between demand and available supplies prompted the government to develop a Gas Utilisation Policy and to go back to administrative control over prices (Gol introduced a price formula for all discoveries under the first six NELP rounds) and over volumes to be allocated to end-consumers. Therefore, in 2008 , the government introduced 
new guidelines called the Gas Utilisation Policy, which effectively took away gas producers' rights to sell the gas they discover on the open market. These guidelines would be applicable for the next five years and be reviewed afterwards. The recent ruling of the Supreme Court in May 2010 regarding the dispute between RIL and RNRL, reaffirms the role of the government in the allocation and pricing of gas.

Page I 10 Currently, the rules of the General Policy for the gas market imply that gas will be allocated according to sectoral priorities set up by the government. This does not imply that the gas is "reserved": if one customer is not in a position to take the gas, the next one on the list becomes eligible. Existing users have priority over Greenfield users. The gas is allocated as follows:

For existing customers:

- Fertiliser producers

- LPG and petrochemicals

- Power plants

- City Gas Distribution (CGD)

- Refineries

- Others.

For Greenfield users, the priorities are:

- Fertiliser producers

- Petrochemicals

- CGD

- Refineries

- Power plants.

The above lists clearly show the preference for fertiliser producers, petrochemicals and power plants as first category customers. CGD usually comes in second position. Gol gave priority to power generators and fertiliser producers, making them the major customers supplied at the lowest rate (APM prices decided by the government) by the state-owned oil and gas companies. Industrial users, which are interested in switching to gas, do not have access to low-priced gas resources and have to pay higher prices to private companies and LNG importers. This makes sense when gas is more economical than the fuel they use (for example naphtha). This situation has changed with the increase of APM prices to USD 4.2/MBtu in May 2010 (prices issues will be discussed in depth in the following chapter). Natural gas pricing and allocation decisions are made by the government at the national level, but the geographical availability of gas and chances for regional development parity have always been a national energy concern. Until recently, gas use was mostly limited to the North West as this is where most of the gas was produced or arriving at LNG regasification terminals. The start of production in the East (KG basin) is likely to change this and provide opportunities for potential customers in this region to switch to gas, if enough supplies are available.

\section{Regulation of downstream markets}

Historically, gas markets were entirely serviced by PSU with prices determined by the central government. From 1987 to 2005, production and transport prices were fixed by the Empowered Group of Ministers (EoGM). The APM mechanism for oil was formally phased out in 2002, but most of the gas produced by ONGC and OIL and distributed by GAIL continues to be sold at APM 
prices. In 2006, the regulator PNGRB was created to set up the bases for a competitive market and has been developing regulations since then.

In the transmission sector, Gol wishes to develop a policy concerning the approval of pipeline construction that would be consistent, market-friendly, and would help avoid duplication of gas transport routes. In December 2006, the monopoly on transmission networks for GAIL was abolished enabling other companies to build and operate networks. The regulator PNGRB set up the Access Code requiring third-party access for one third of the capacity and setting the tariffs of transportation for third parties. PNGRB has therefore to determine tariffs for existing pipelines as well as for pipelines authorised by the government (before PNGRB was created). Typically, transport along the Hazira-Vijaipur-Jagdishpur pipeline costs USD 0.58/MBtu; GAIL proposed to charge USD 0.88/MBtu for its $572 \mathrm{~km}$-long Dahej-Uran-Panvel pipeline. For its $1400 \mathrm{~km}$-long East-West pipeline (EWPL), RGTIL opted for a two-zone tariff and wanted to charge USD 0.3-0.4/MBtu for the first zone and USD 1.25/MBtu for the second zone.

Permission for the routes is given after the entity provides performance and bond guarantees. If they do not fulfil the obligations of the "common carrier principle", the ministry can revoke the approval. To avoid this risk, companies propose competitive pipelines often heading to the same markets. This raises the issue of the duplication of pipelines. So far, the pipelines licensing policy proved to be highly conditional in following all those criteria:

- The government may come up with conditions in cases where the pipelines of two companies cross at a point;

- The company that lays its pipeline first may be able to claim ownership of the junction while the other may have to follow security-related regulations. The company completing the project first would enjoy the status of pipeline owner with the power to block the other project in case of conflict of interest;

- If the crossing of two pipelines poses safety risks, the other pipeline would have to seek government permission and follow stringent guidelines for crossing the owner's pipeline.

Regarding gas distribution, PNGRB has been organising bids to develop gas distribution infrastructure in cities. This includes distribution to residential users, and small and middle enterprises (SME) as well as CNG. Companies are given exclusive rights for five years. Licenses are to be awarded through an open competitive bidding process, with a level playing field for both domestic and foreign entities. Several bids took place in 2008 and 2009. As of 2009, only 41 cities had distribution gas networks for domestic use but PNGRB plans to extend the coverage to 250 cities within the next ten years.

Several issues explain the lack of development. First, the regulatory framework is unclear and not conducive to attracting private investment. City gas has a low priority according to the government's allocation policy but winners of the bids have nevertheless to secure gas supplies. Furthermore, in order for a city to receive gas, it must be connected to the main transmission system, which is still inadequate as it consists mainly in pipelines in the northwest region and the EWPL. There are therefore large transportation pipeline requirements for major cities in the South, the North and the East to be connected. Finally, a regulatory issue appeared in February 2010, when the Delhi High Court ruled that PNGRB did not have the authority to issue city gas licences, because the government did not notify Section 16 of the Act explicitly giving these powers to the board. In the meantime, the power of authorising companies which have won the previous bids is back in the hands of the MoPNG. In July 2010, the government finally notified the Section 16, empowering the downstream regulator to issue CGD licences. 


\section{Exploration and production}

The upstream sector is largely dominated by two state-owned companies, ONGC and, to a lesser extent, OIL. There were some JVs created with private companies before the government launched its New Energy Licensing Policy (NELP) but these JVs were also dominated by ONGC

Page | 12 and OIL. Over the last decade, the government has opened the upstream sector to both private and foreign companies. While this has effectively attracted private Indian companies such as RIL or a few foreign companies such as Cairn, major IOCs remain almost absent from the Indian upstream sector, largely due to government policy on prices (see sections on Domestic production and Prices). BG is one of the exceptions through its presence in the Tapi field. The opening of the upstream sector has also attracted a state-government-owned company, Gujarat State Petroleum Company (GSPC), in which the state of Gujarat owns 95\%. GSPC took part in the pre-NELP licensing rounds as well as in some NELP licensing rounds.

Until April 2009, the share of private companies in license ownership as well as in production was significantly smaller than the state-owned companies' share. This translated into the higher number of fields operated by these two companies, in particular by ONGC. As of 1 April 2009, there were 125 gas fields in operation countrywide, of which 118 were owned by ONGC, 3 by OIL and 4 fields by private JVs (MoPNG, 2009b). ${ }^{2}$ ONGC has also 219 licenses in fields producing both oil and gas; OIL owns 15 of such licenses; and private JVs have 27 licenses of this type.

Most of the gas was produced by ONGC up until 2009. In FY 2009/10, ONGC produced $23.1 \mathrm{bcm}$ in India, a slight increase over $22.5 \mathrm{bcm}$ in $\mathrm{FY} 2008 / 09$. This compares to a total production of $46.5 \mathrm{bcm}$ and $31.8 \mathrm{bcm}$ in $\mathrm{FY} 2009 / 10$ and $\mathrm{FY} \mathrm{2008/09}$ respectively. Although the situation regarding the operatorship of fields is not likely to change massively in the future as ONGC won half of the awarded licenses during the $8^{\text {th }}$ round of NELP, the share of JVs and private companies in production output is already growing massively from $7.3 \mathrm{bcm}$ to $19.4 \mathrm{bcm}$ from FY 2008/09 to FY 2009/10. Indeed, RIL's KG-D6 field produced $14.4 \mathrm{bcm}$ during FY 2009/10, more than half of ONGC's gas production. The new discoveries and the potential of fields owned by private companies will allow them to play an increasingly important role in the sector.

\section{LNG}

ONGC and GAIL are also present in the LNG sector through their participation in Petronet LNG Limited, a joint venture of GAIL, ONGC, IOCL, Bahrat Petroleum (BPCL), GDF Suez, and the Asian Development Bank (ADB). Petronet owns one of the two existing LNG terminals (Dahej) while a second one is expected to start in 2010. The other LNG terminal (Hazira) is owned by two foreign companies - Shell and Total. Other players, including power companies and banks, are planning to enter the LNG scene through new LNG terminals projects, but not all of the planned terminals will actually move forward (see section on Imports for more details).

\section{Transport}

There are two main transportation companies, the former public sector monopoly, GAIL, and a new entrant, Reliance Gas Transportation Infrastructure Ltd (RGTIL), a company privately owned by RIL. Other players in the transport sector are more regional such as Gujarat State Petronet Ltd (GSPL), part of GSPC. Historically, the transport infrastructure has been developed

2 OIL operates in Assam and Rajasthan States, whereas ONGC operates in the Western offshore fields and in other states. 
to link production centres or LNG import terminals located mainly in the northwest coast to the primary consumption centres located in the North West. GAIL had a monopoly in the transport sector and was in charge of developing the Natural Gas Grid (NGG). The government decided to encourage the construction of more transmission pipelines in the country and ended GAIL's monopoly in December 2006, enabling RIL to step in. In 2007, GAIL and RIL signed a gas transmission agreement (GTA) to share each other's pipelines for transmission of natural gas from the KG basin fields. The agreement provided for the transportation of gas from the KG basin in the east coast of India through GAIL's network, and for booking of capacity by GAIL in RGTIL's EWPL. GTA was a framework agreement for booking of capacity through execution of capacity tranche agreements (CTA).

GAIL has a network of about $7850 \mathrm{~km}$ with transmission capacity of about $157 \mathrm{Mcm} / \mathrm{d}$, representing $78 \%$ of India's transmission business. The very first major long-distance gas transportation pipeline, the Hazira-Vijaipur-Jagdishpur (HVJ) line, was built by GAIL. It connects ONGC's delivery point near Hazira in Gujarat to demand centres in the North West including Jagdishpur in Uttar Pradesh and Vijaipur in Madhya Pradesh. It is $3187 \mathrm{~km}$ long, with a capacity of around $34 \mathrm{Mcm} / \mathrm{d}(12.4 \mathrm{bcm} / \mathrm{y})$ and serves a number of large power and fertiliser plants, besides smaller industrial units lying along its route. GAIL has recently constructed a few other pipelines, connecting the LNG terminal of Dahej to Vijaipur and Uran and the power plant at Dabhol to Panvel. GAIL has also executed the Hazira-Bijaypur-Jagdishpur (HBJ) trunk pipeline connecting Gujarat to Uttar Pradesh. GAIL is still pursuing plans to lay pipelines between indigenous gas fields, imported LNG and different demand centres.

In 2008, RIL completed the $1400 \mathrm{~km}$ long EWPL connecting Kakinada in Andhra Pradesh to Baruch in Gujarat. EWPL connects with GAIL's HVJ line and Dahej-Vijaipur pipeline network at Ankot in Gujarat, Dahej-Uran and Dabhol-Panvel pipeline network at Mashkal in Maharashtra. What RIL has achieved in the transmission sector in such a short time frame (two years) is absolutely remarkable and their fast construction is a stark contrast with the slow progress of GAIL projects over two decades.

Meanwhile GSPL, which is a pure transmission company, operates a grid of $1420 \mathrm{~km}$. It intends to expand its grid reaching regions in the North but also in the East. The company has submitted four expressions of interest to PNGRB: the $1670 \mathrm{~km}$ Mehsana-Bhatinda pipeline, the $740 \mathrm{~km}$ Bhatinda-Jammu-Srinagar pipeline, the West-East pipeline from Surat to Paradip (1680 km) and the $1585 \mathrm{~km}$ Mallavaram-Bhilwara pipeline.

Map 1 shows the existing pipeline infrastructure highlighting that large parts of India do not yet have access to gas due to lack of infrastructure. The size of the country and the fact that historically most of the production was located in the North West explain this situation. The start of KG-D6 off the east coast provides an opportunity to supply new cities, in the South Chennai, Bangalore, Tuticorin - but also in the North East. Petronet's new LNG terminal in Kochi (southwest coast of India) planned to start in 2012 could also enhance the development of pipelines in the southern region. RIL and GAIL are gearing up to start the second phase of construction of pipelines to transport gas from the Krishna-Godavari Basin to the southern parts of the country. The pipelines should be completed by 2012 with an estimated investment of INR 2300 crore $^{3}$ (USD 0.5 billion) from RIL. GAIL announced in August 2010 that it would invest about INR 30000 crore (USD 6.4 billion) over the next three years to build over $6600 \mathrm{~km}$ of pipeline and connect cities in Uttar Pradesh, Uttarakhand, Punjab, and Haryana by 2013. In particular, GAIL plans to lay $1389 \mathrm{~km}$ of pipeline from Dabhol to Bengalore and to link the future Kochi LNG terminal to Mangalore (1 $114 \mathrm{~km})$. GAIL is also investing to increase capacity of

3 A crore is an Indian unit equal to 10 million. 
existing pipelines. GAIL is also developing the network in the North, enhancing the capacity of the Dahej-Vijaipur and Vijaipur-Dabri pipeline and building to Dabri-Bawana-Nangal pipeline and the Chainsa-Jhajjar-Hissar pipeline to supply regions in the North such as Punjab and Haryana. Another pipeline, the $2050 \mathrm{~km}$ Jagdishpur-Haldia pipeline, is planned to link the existing network to the north-eastern part of India. RIL was authorised to build the $600 \mathrm{~km}$ long Page | 14 Kakinanda-Chennai pipeline to be commissioned by the second quarter of 2012, the $1140 \mathrm{~km}$ Kakinada-Basudebpur-Howrah pipeline as well as the Chennai-Bangalore-Mangalore pipeline and the Chennai-Tuticorin - all of them also expected by 2012.

Map 1: Existing and proposed gas pipelines in India

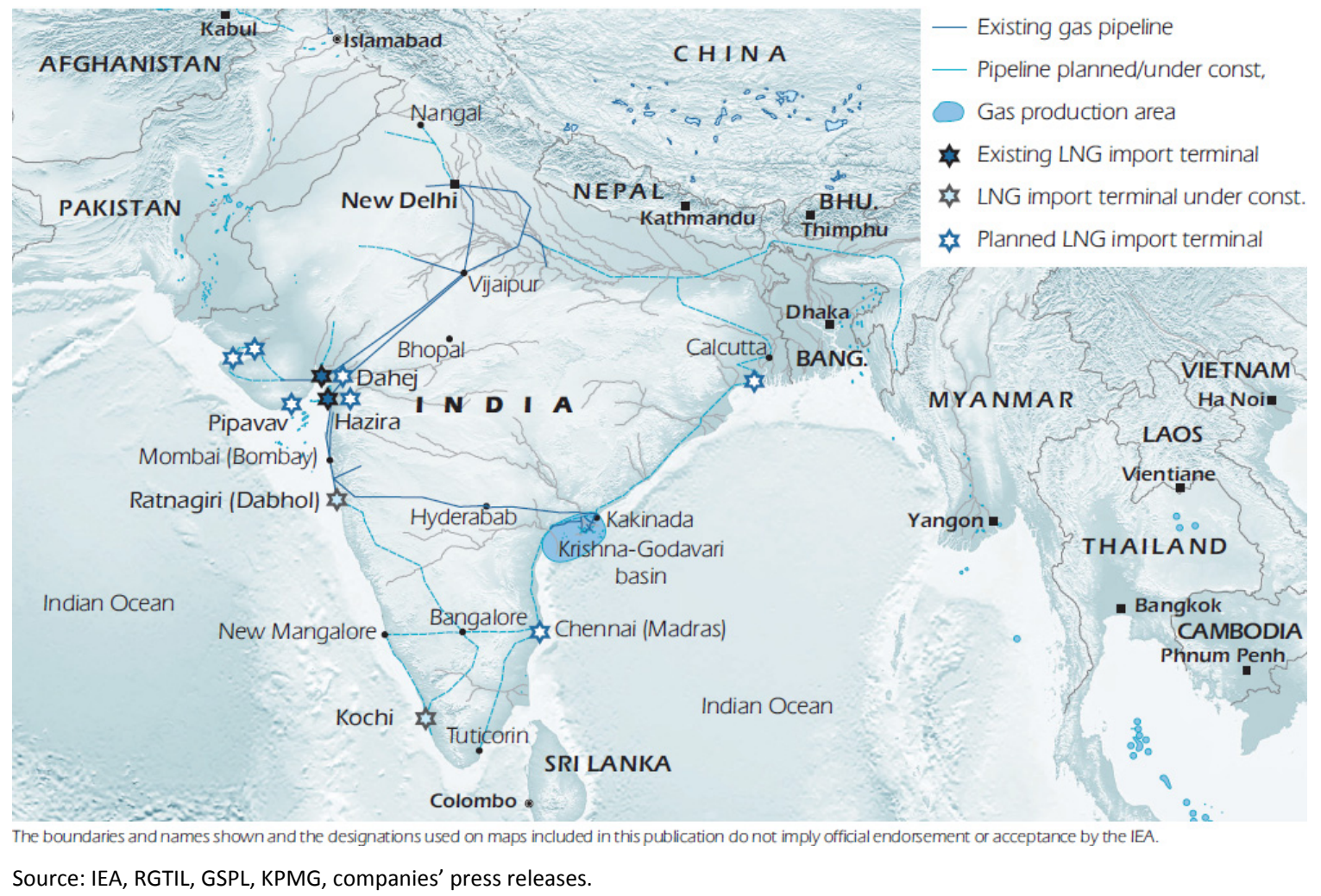

\section{Retail}

In retail, GAIL has also a dominant position, while OIL markets the gas it produces itself for historical and geographic reasons. The gas produced by ONGC in the western offshore fields and in other states and a part of gas produced by the JVs is marketed by GAIL. The gas produced by Cairn Energy and GSPC is sold directly by them. Some regional companies serving limited areas have also developed over the past two decades, but in most cases, are in joint ventures with GAIL, regional governments and other companies: Indraprastha Gas Ltd (IGL) (Delhi), Mahanagar Gas (Mumbai) and Gujarat Gas Company Ltd (GGCL) (Gujarat), who all distribute piped gas and CNG. IGL was set up in 1998 as a JV of GAIL, BPCL and the government of Delhi in order to improve air quality. Mahanagar Gas is a JV of GAIL, BG and the government of Maharashtra. Only GGCL is privately owned with BG owning $65 \%$ of the share, and financial institutions and public the balance.

The scarcity of supply compared to potential demand and lack of sufficient infrastructure have hampered the development of CGD and prevented new players from entering the retail market. 
Apart from GAIL and RIL, a few players have drawn up ambitious plans to roll out city gas infrastructure across a number of cities in the country. States that are likely to see further activity include Maharashtra, Andhra Pradesh - both crossed by EWPL, Uttar Pradesh, Madhya Pradesh, Rajasthan - all close to the HVJ pipeline, and Haryana in the North and Karnataka, Kerala in the South. Currently, GAIL and RIL are both trying to develop CGD licenses and gain market shares in the retail sector by winning licenses proposed by PNGRB. In 2008, they both expressed interest in the 60 licenses offered with RIL submitting interest for 54 cities and GAIL for eight cities, resulting in a limited overlapping consistent with an agreement between the two companies.

Table 2: Bidding rounds for CGD licenses in 2009

\begin{tabular}{llll}
\hline Bidding Round & City & State & Winner \\
\hline March 2009 & $\begin{array}{l}\text { Devas } \\
\text { Kakinada }\end{array}$ & Madhya Pradesh & GAIL \\
& Andhra Pradesh & Bhagyanagar Gas (JV of \\
& Kota & & GAIL/HPCL) \\
Meerut & Rajasthan & GAIL \\
Sonepat & Uttar Pradesh & GAIL \\
Mathura & Haryana & GAIL \\
& Rajahmundry & Uttar Pradesh & DSM Infratech \\
Yanam & Andhra Pradesh & RIL* \\
& Sehdol & Andhra Pradesh & RIL* \\
& Chandigarh & Madhya Pradesh & RIL* \\
Allahabad & Haryana & Adani Energy/IOC* \\
& Ghaziabad & Uttar Pradesh & Adani Energy/IOC* \\
& Jhansi & Uttar Pradesh & IGL* \\
\hline
\end{tabular}

Source: GAIL, Bhagyanagar Gas, The Economic Times, Business Standard.

Note $\left({ }^{*}\right)$ : the second auction was not completed as IGL challenged PNGRB's authority to issue CGD licences.

Both companies have also bid in the two rounds organised in 2009. The first bidding round in March 2009 attracted eight companies for six cities (see Table 2). GAIL won the rights for five of these cities (one through a JV) and DSM Infratech the last one. GAIL has started implementing the projects. The second round in June 2009 included seven cities. But IGL claimed it had been authorised to distribute gas in Ghaziabad by the government and challenged PNGRB's authority to issue licences in the Delhi High Court. It also claimed to have already been working in the city since 2002. In January 2010, the Court ruled that PNGRB had no powers to issue CGD licenses. Afterwards, Gol was in charge of issuing CGD licenses: it authorised winners of the first round of auction conducted by PNGRB, and confirmed IGL's right to develop the distribution network in Ghaziabad. Since PNGRB has been empowered to issue CGD licenses, the board is keen to challenge the authorisation granted to IGL for Ghaziabad's network and pursue its case in the Supreme Court.

The factors that will determine the development of city gas distribution in the future are:

- a clear regulatory framework both for the entity responsible for the promotion of city gas distribution and regulation of existing players, and for the layout of transmission pipelines across the country

- cleaner cities policy

- sufficient gas supply

- pricing and price reform for substitute fuels. 


\section{Pricing}

The pricing system in India is relatively complex due to the existence of a dual pricing resulting in two distinct gas markets. In one market, gas produced by PSUs is allocated to specific customers according to the Gas Policy and sold under the Administrative Pricing Mechanism (APM) decided by the government. In the other one, gas was produced by JVs or private companies and sold at prices agreed according to the PSCs. As of April 2009, around $57 \mathrm{Mcm} / \mathrm{d}$ is APM gas and $46 \mathrm{Mcm} / \mathrm{d}$ non-APM gas (which includes $20 \mathrm{Mcm} / \mathrm{d}$ produced by Joint Ventures between ONGC \& the private sector under Production Sharing Contracts (PSCs) and $26 \mathrm{Mcm} / \mathrm{d} \mathrm{LNG).}$

This situation clearly called for reforms, but these had been delayed until May 2010 when the government decided to increase APM prices to USD 4.2/MBtu and give freedom to ONGC and OIL to market additional gas produced at market rates. Indeed, the share of APM gas had been declining while the share of non-APM gas had been increasing. In 2007/08, APM gas sold by public sector companies accounted for $60 \%$ of the domestic market, but only $55 \%$ for the following year. It is estimated to be down to $35 \%$ as of early 2010 .

\section{Gas price evolution}

The government has always had a key role in deciding gas prices for the historical reasons discussed in the first part of this Working Paper.

- From 1959 to 1987, gas prices were fixed by the PSUs ONGC and OIL.

- In 1987, the Empowered Group of Ministers (EGoM) was put in charge of determining gas prices. Over 1987-2002, three committees were successively in charge of the three five-year periods. Typically, gas price included a producer price and a transport tariff. On top of this, a contribution to the Gas Pool Account (created in 1992) was set up, to compensate companies involved in E\&P, marketing and transport of gas for their low margins in the development and sales of gas. ${ }^{4}$ Initially the producer prices reflected long-term production costs and increased in 1992 from INR 1 400/1000m (USD 0.78/MBtu) to INR $1500 / 1000 \mathrm{~m}^{3}$ (USD 0.84/MBtu)..$^{5}$ In 1997 , Gol decided to put gas prices at landing point at parity with a basket of LS/HS fuel oil prices with the view to achieve full parity by 2001-02. A floor

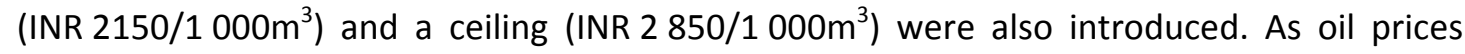
increased in the early 2000s, the project of full parity was abandoned and prices stayed at the ceiling level. By 2005, they were $34 \%$ of fuel oil prices.

Transport prices were also fixed by the EGoM. Typically transport along the HBJ increased

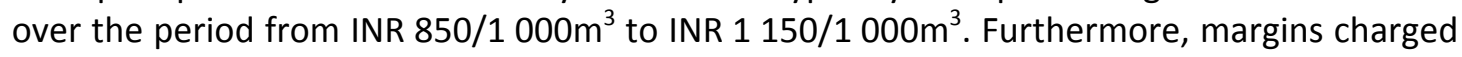
by marketers such as GAIL are also decided by the government. These marketing margins differ depending on the origin of the gas (LNG, domestic gas field).

Issues had already been arising with respect to different costs of production between the companies, the likelihood of importing more expensive gas in the future and increasing international oil and gas prices over 2000-05. On the transport side, issues included no distance-related charges for existing pipelines such as HBJ and different end-user taxes. In

4 In particular, the sums on this account were used to compensate OIL for subsidized gas prices in the North East, compensate PSUs for increases in operating costs, payment of higher prices for the new JV and exploration and development of small fields.

5 All prices are based on gas with a calorific value of $10000 \mathrm{kcal} / \mathrm{m}^{3}$. 
2002, the APM system was formally abolished for oil but APM prices remained for gas produced by PSUs.

- In 2005, the price of APM gas of ONGC and OIL was revised. Based on recommendations of the Tariff Commission, the Cabinet Committee on Economic Affairs decided that APM gas prices would be increased. All available APM gas would be dedicated to power generators, fertilisers as well as specific end users covered by Court orders and small-scale consumers having allocations up to $0.05 \mathrm{Mcm} / \mathrm{d}$. At that time, ONGC and OIL produced about $55 \mathrm{Mcm} / \mathrm{d}$ APM gas from nominated fields. In July 2005 , the price of APM gas was increased from INR $2850 / 1000 \mathrm{~m}^{3}$ (USD 1.59/MBtu) to INR $3200 / 1000 \mathrm{~m}^{3}$ (USD 1.79/MBtu) except in the northeast region where gas was sold at $60 \%$ of the revised price, i.e. INR $1920 / 1000 \mathrm{~m}^{3}$ (USD 1.07/MBtu). In 2007, the Tariff Commission proposed to increase ONGC's price to INR $3600 / 1000 \mathrm{~m}^{3}$ (USD 2.01/MBtu) and OIL's price to INR $4040 / 1000 \mathrm{~m}^{3}$ (USD 2.26/MBtu), but this increase did not happen.

- APM gas prices for the transport sector (CNG), small industries and consumers would be progressively increased from INR $3200 / 1000 \mathrm{~m}^{3}$ (USD 1.79/MBtu) over the following years to reflect the market price. As they became the second category after fertilisers and power producers, small users/CNG saw prices increasing from INR 3 200/1000m (USD 1.79/MBtu) to INR $3840 / 1000 \mathrm{~m}^{3}$ (USD 2.15/MBtu) in 2006 (INR $2304 / 1000 \mathrm{~m}^{3}$ in the North East).

- Meanwhile, non-APM gas was sold to consumers at the price at which GAIL buys from producers at landfall point. In this case, it depends whether gas is produced under PSC predating NELP, NELP gas or LNG.

- Part of the gas is sold under PSCs dating from pre-NELP; this is notably the case for gas from Panna Mukta Tapti (PMT) and Raava. Their price is linked to the 12 months average of fuel oil prices. For PMT, the ceiling was progressively increased over the years from USD 3.11/MBtu initially to USD 3.86/MBtu in 2005 and USD 4.75/MBtu in April 2006. Raava gas prices were increased to USD 3.5/MBtu in 2006.

- Gas sold under PSCs from the NELP has a different regime. The PSC contractor is required to sell the gas at a competitive arms-length price to the benefit of both parties (the government and the contractor), and the price formula has to be approved by the government. Indeed the company has to support the entire investment, honour the minimum work programme of committed exploration, and pay a penalty in the event of their failure. According to the PSC, the company recovers the investment during the first years, while the government's share of petroleum profits is the lowest. The government's share increases with cost recovery. Therefore, the valuation of the gas produced from the NELP fields is very important for the government revenues. The price level that RIL received for the KG-D6 gas for the first five years of production (until 2014) is USD 4.21/MBtu.

In May 2010, the MoPNG increased APM gas prices from USD 1.79/MBtu to USD 4.2/MBtu, a price level similar to KG-D6 gas. The price is to be fixed in USD and converted in rupees based on the exchange rate of the previous month. The price of USD 4.2/MBtu excludes any transportation charge, margin and taxes. Marketing margin typically range between USD 0.1/MBtu and USD 0.2/MBtu. Users in the North East will pay $60 \%$ of that price (USD 2.52/MBtu), with the government paying the difference to PSUs. Meanwhile, GAIL, which is marketing APM-gas, has been allowed to charge a margin of INR $200 / 1000 \mathrm{~m}^{3}$ (USD $0.112 / \mathrm{MBtu}$ ), which could translate into an estimated annual revenue increase of INR 150-200 crore. MoPNG also allowed ONGC and OIL to market gas produced by them at market rates. ONGC was given 
permission to sell gas from its C-series fields in Mumbai offshore at USD 5.25/MBtu, even higher than KG-D6. These fields are expected to produce $1 \mathrm{bcm} / \mathrm{y}$.

On top of gas produced domestically, LNG has become an increasing part of the supply mix of India. The current LNG prices for the two operating terminals are the following:

Page | 18 - Long-term contract with Qatar's RasGas (Dahej): for the first five years, Petronet paid a fixed-price agreed in the contract (USD 2.53/MBtu for $5 \mathrm{mtpa}$ ). In January 2009, this price was raised to USD 3.12/MBtu while volumes increased to $7.5 \mathrm{mtpa}$ in Q4 2009.

- Short-term contracts: Petronet negotiated with RasGas until December 2008 for $1.5 \mathrm{mtpa}$, Petronet paid USD 8.50/MBtu, but the price for end-consumers was pooled with the USD 2.53/MBtu Petronet paid for LNG under the long-term contract.

- Spot cargoes: during the summer of 2009, several companies including Petronet and GAIL contracted spot cargoes for Dahej. Delivered prices were at USD 4.50-4.75/MBtu. Similar prices were observed for Hazira, a sharp drop compared to the cargos imported in October 2008 at USD 20-22/MBtu.

- Petronet's terminal in Kochi to be commissioned by 2012 has contracted to receive LNG from Exxon Mobil's $25 \%$ stake in Australia's Gorgon project in all likelihood at much higher prices than existing LNG contracts. LNG supplies will start in 2014-15.

The previous wide disparity between APM prices and non-APM prices, whether for gas from pre-NELP or NELP, has narrowed. Under long-term contract, LNG is at a middle point between APM and non-APM prices but gas sold under the new long-term contracts is likely to be more expensive. Spot LNG prices are usually the highest but depend on global market conditions: they were effectively at the same level as non-APM prices during the summer of 2009 (see Table 3).

Table 3: Gas price differentiation on the Indian gas market (2010)

\begin{tabular}{l|l}
\hline Gas source & Import or production price \\
\hline OIL & USD 4.2/MBtu (APM regime) (USD 1.8 up to May 2010) \\
ONGC & USD 4.2/MBtu (APM regime) (USD 1.8 up to May 2010) \\
LNG long-term contract & USD 3.12/MBtu, Dahej terminal \\
RIL & USD 4.215/MBtu \\
C Fields & USD 5.25/MBtu \\
Panna Mukta Tapti field & USD 5.73/MBtu \\
LNG spot & USD 5-6/MBtu mid 2010 but has been ranging between USD 4.75 \\
& and 20/MBtu in the period from October 2008 to mid 2010 \\
\hline
\end{tabular}

Note: The end-user delivery price would include a transportation price.

Source: IEA, Indian Oil and Gas, Industry announcements and presentations.

\section{Pricing issues}

The pricing issue in India has always been quite complex. Firstly, APM gas supplies have been declining while non-APM gas saw a dramatic increase in volume and share. Furthermore, APM gas has been allocated in priority to power producers and fertilisers, two sectors expected to see their demand increasing over the coming decade (see section on demand). While the MoPNG has been pushing for higher prices to limit losses from the PSU, this has met with strong resistance from the Ministry of Power and Ministry of Chemicals and Fertilisers. The subsidies to fertilisers have already multiplied by five over the last five years to reach INR 75849 crore (USD 16.6 billion) in 2008/09. 
From the supply side, keeping artificially low APM prices often sends the wrong signals: indeed, gas prices have to be high enough in order to attract upstream investments, and cover production costs and the recovery of capital in order to limit under-recoveries from PSUs (the difference between the international market prices and the domestic retail price). These, unsurprisingly, complained that low prices had been resulting in substantial losses for them. Furthermore, India is likely to need increasing LNG supplies and has to be able to contract additional LNG supplies on global markets or spot LNG cargoes when these are available to meet a growing supply-demand gap. Even if the slope in long-term contracts is no longer at the 0.17 seen in the Asian region in 2008, it is certainly likely to result in higher prices than the USD 3/MBtu price with Qatar.

On the demand side, the challenge is to perform a transition to prices closer to market prices while maintaining the consumer's competitiveness. KG-D6 gas price for the first five years of production, namely USD 4.21/MBtu, will soon represent around half of India's supplies. This price, more than twice the former APM price level fixed by the government, has unsurprisingly become a reference point. Being a private sector company, RIL cannot sell gas at under cost; therefore their clients have to be able to pay cost-plus for any of their gas.

Indeed gas availability and affordability for customers are crucial for gas development in India. Demand for gas is infinite at USD 2-3/MBtu but limited at USD 7-8/MBtu for Indian major, priority customers - fertiliser production and power generation. There are two direct competing fuels for gas in these two sectors: coal (in the power sector) and naphtha, as well as the option to produce fertilisers offshore. Gas represents currently a small portion of total power capacity. In most cases, coal-fired generation will be cheaper than gas, but when one compares a coalfired plant is located far from coal fields or using imported coal with a gas-fired plant near the existing gas transmission infrastructure, this will not be the case. Certainly, these two sectors will be tested by the increase of APM prices. (The issues regarding the competitiveness of gasfired generation are looked at in more details in the Demand section.) The fertiliser industry represents a big issue as increasing the gas price is likely require some policy solution: this could be increasing the subsidies of these customers, something that the finance ministry is unlikely to accept easily, or produce fertiliser in other countries which would face opposition from the fertiliser producers themselves and would also affect India's self sufficiency with respect to agricultural production.

The pricing issue is not limited to gas: diesel, gasoline, kerosene, and LPG prices are kept low in India in order to insulate consumers from high international oil prices. On 25 June 2010, the EGoM decided to let oil marketing companies set the price of some oil products. Previously, retail prices were determined by the government and oil marketing companies were forced to sell petrol and diesel below market prices. The government used to partly reimburse the stateowned oil marketing companies for under-recoveries. Significant under recoveries have been seen since 2005, reaching close to USD 30 billion in 2008/09 (IEA, 2010a). Since 2005, the government has increasingly issued billions of Indian rupees to these companies to counteract the under-recoveries. This has been made via "oil-bonds" which amounted to USD 20 billion in 2008/09. This has a significant fiscal impact which is only becoming worse: the deficit in nominal terms more than doubled from $5.7 \%$ of GDP in $2007 / 08$ to $11.4 \%$ in $2008 / 09$. There is therefore a need to move towards market-based petroleum pricing reform while protecting vulnerable customers. Petrol prices recently increased, while diesel prices will be deregulated. LPG and kerosene have been and will continue to be subsidised for domestic users. Regarding gas, ONGC estimated losses on 2008/09 gas sales to over USD 1 billion due to the low sale prices to fertilisers and power producers compared to the increased costs of gas production. 


\section{Which way forward?}

There have been many attempts undertaken by Indian governments to liberalise/revise the dual system until the decision was taken in May 2010. Several suggestions had been made: one was to increase the price paid to ONGC and OIL to USD 2.3/MBtu in 2010, to link it to a Wholesale

Page | 20 Price Index in the future, or to increase it progressively to USD 4.2/MBtu by 2013. Another idea developed by the Ministry was a uniform domestic price instead of a multitude of prices. This would be achieved through a removal of the dual APM/market pricing by gas pooling, which would stabilise prices and thus serve as a benchmark.

The government has made a big leap forward by increasing APM prices directly to USD 4.2/MBtu, creating a reference price representing currently to an estimated two thirds of gas supplies. Additional changes may happen. The idea of pooling gas prices is still under study. The question is now to see how this will affect the market in the future and how gas users, which had been allocated cheaper gas than the new reference price, will be adversely affected. Whatever the choice, a new future pricing mechanism would need to incentivise gas production, attract new LNG supplies, while being transparent to attract foreign or private investors. 


\section{Domestic production}

\section{Historical trends}

Proven and indicated reserves of natural gas in India were $1074 \mathrm{bcm}$ as of 1 April 2009, slightly up from $1050 \mathrm{bcm}$ as of April 2008. The vast majority $(787 \mathrm{bcm}$ ) represents offshore gas ( $287 \mathrm{bcm}$ is onshore) according to the Ministry of Petroleum and Natural Gas. ${ }^{6}$ Exploration and development drilling in India is significant as domestic production has grown from $12 \mathrm{bcm}$ in the early 1990 s to levels around $30 \mathrm{bcm}$ since 2000, before increasing dramatically during 2009. The fiscal year $2008 / 09^{7}$ saw the drilling of 122 exploratory wells and 250 development wells working with total metreage of $888000 \mathrm{~m}$, the highest levels in last five years.

Figure 1: Domestic net gas production by region

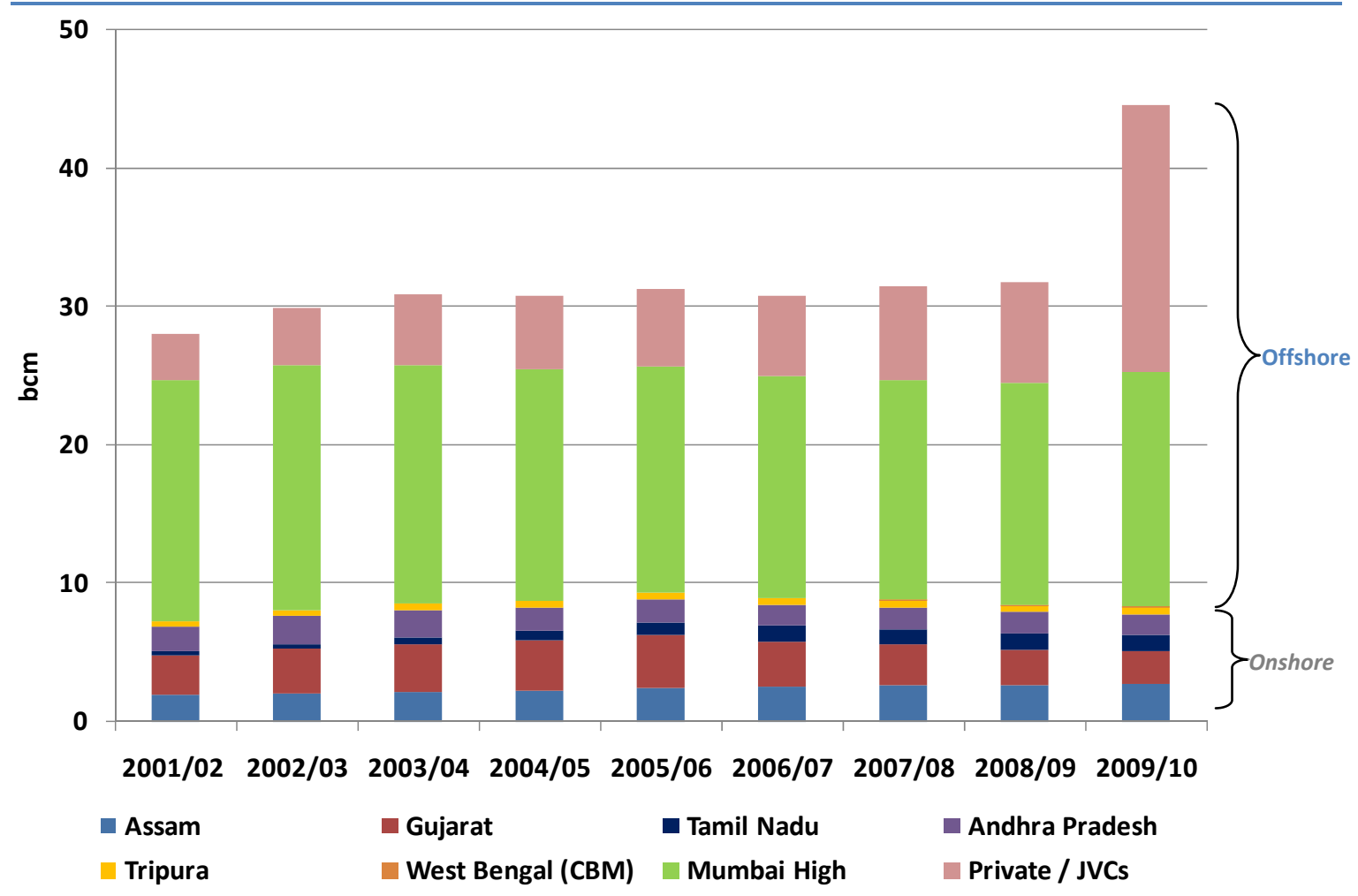

Source: Ministry of Petroleum and Natural Gas of India.

Production has been almost flat at $30-32 \mathrm{bcm}$ since 2002, but jumped to $46 \mathrm{bcm}$ in $2009 / 10 .{ }^{8}$ Around three quarters of the gas production came from the Western offshore area. The share of offshore production increased to $80 \%$ in 2009/10. Fields located in Gujarat, Assam and Andhra Pradesh are the major sources of onshore gas. Smaller quantities of gas are also

6 This compares with $1185 \mathrm{bcm}$ reported by BP and $1085 \mathrm{bcm}$ reported by Cedigaz at the end of 2009. The world's total proven gas reserves are estimated at $187 \mathrm{tcm}$ (BP) (Cedigaz, $189 \mathrm{tcm}$ ).

7 In India, many data are given for the fiscal year, a period starting on 1 April and finishing on 31 March. The Petroleum Planning \& Analysis Cell (PPAC) and the Ministry also provide calendar year data on their website and in their annual reports.

8 IEA statistics. Statistics may slightly differ from the Ministry's data due to use of different calorific values or inclusion of gas flared. 
produced in Tamil Nadu, Tripura and Rajasthan as can be seen in Figure 1, but this changed due to the start of the offshore eastern coast Krishna Godavari (KG) field in April 2009.

Despite a relatively long E\&P history, one major issue concerns the fact that no full geological survey of the sedimentary basins has been completed (see Figure 2). This issue, which is recognised by the government, is nevertheless critical to attract investors.

Figure 2: Level of exploration

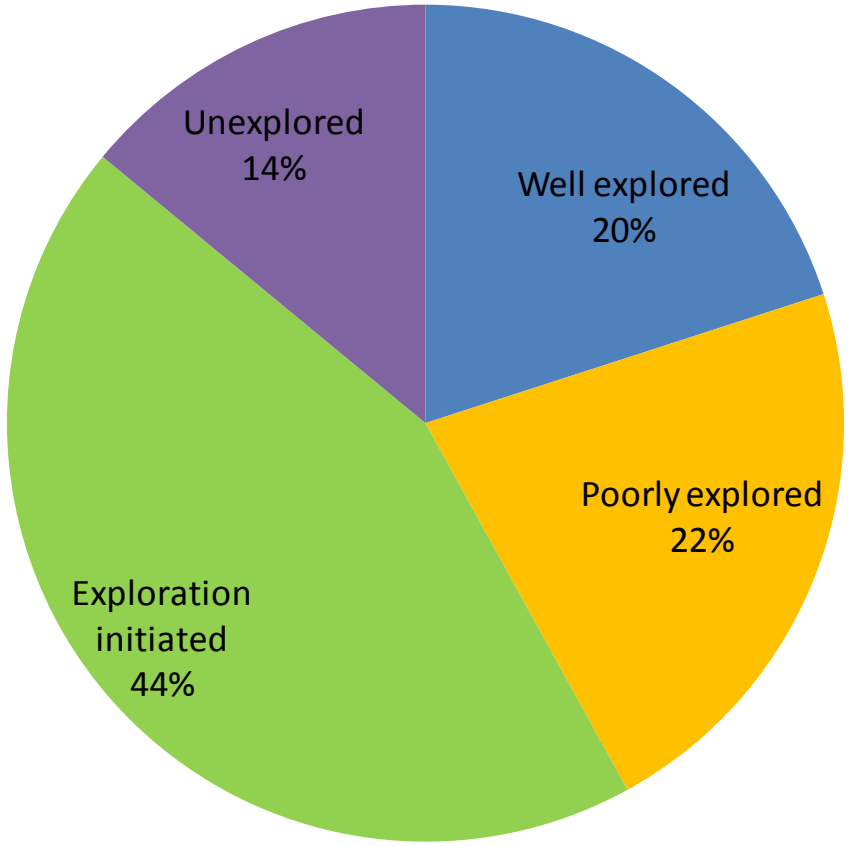

Source: Opportunities in Oil and Gas Markets, R S Sharma, Chairman of ONGC, September 2009.

As already mentioned, ONGC and OIL are the two dominant players with private companies playing an increasing role. All natural gas produced from existing fields in nominated blocks of ONGC and OIL is treated as Administered Pricing Mechanism (APM) gas. However, both ONGC and OIL will now be allowed to sell any production from new fields in their blocks at market prices that are set and approved by the government to encourage the two companies to invest in upstream development (see previous section on pricing). Meanwhile JV gas from allocated fields before NELP is sold at "market prices", set and approved by the government. Gas production by JVs and private companies has been increasing, a trend likely to continue over the upcoming years.

The recent major development is the Krishna Godavari KG-D6 (block DWN-98/3) field operated by Reliance Industries Ltd. (RIL). The field is located in the Bay of Bengal off the eastern coast of India and produced $14 \mathrm{bcm}$ in FY 2009/10. As of early 2010, it has reached a production level of $60 \mathrm{Mcm} / \mathrm{d}(22 \mathrm{bcm} / \mathrm{y})$ and is expected to reach an annual plateau production of $30 \mathrm{bcm}$ by 2012, similar to India's domestic production level over the past decade.

\section{The New Exploration Licensing Policy}

The evolution of Indian gas production over the past years is due entirely to the New Exploration Licensing Policy. There had already been exploration bidding rounds organised over 1979-98 - before NELP began - allowing private companies to bid, but they were not very successful. Four rounds took place during the period 1979-91 and five during 1994-95. Only 148 bids were made for the 349 blocks offered and only 28 contracts signed. Even when 
contracts were signed, the delays were important before getting the approval from the relevant agencies. Furthermore, retail price caps were hindering investment in new gas production and supply infrastructure, while private and foreign oil and gas companies had little access to the Indian market. By the end of the 1990s, as much as half of India's gas demand was unmet (MoPNG, 2000).

In 1997, the Government of India adopted the New Exploration Licensing Policy (NELP) based on production-sharing contracts, in order to solve these problems - especially the supply shortages. The policy, aiming at creating a more investor-friendly framework, consisted of the following steps:

- deregulation of the upstream sector

- opening the doors to private and foreign investors

- promise to give companies the right to sell gas at market prices on the domestic market but with the government having a final say on pricing

- gradual evolution to full market pricing.

The first round started in January 1999. The NELP allowed private companies to bid for oil and gas exploration blocks, with no limitation on the number of blocks. Private investors were guaranteed attractive tax rules (such as a seven-year tax holiday from start of production or no customs duty on imports for petroleum products) and also the freedom to sell their gas at a price agreed with the government. There was no carried interest by PSU (India's National Oil Companies [NOCs]). Previously, there was an option (but not a requirement) for PSUs to take participation up to $40 \%$; this was suppressed in the NELP. Conditions for deepwater projects were made more attractive by being charged lower royalties than other projects.

In parallel to the NELP, India introduced a Coalbed Methane (CBM) policy. The CBM Policy has also been quite successful. After three rounds of CBM, contracts for 23 CBM exploration blocks have been signed. More than $170 \mathrm{bcm}(6 \mathrm{tcf})$ of reserves have already been established in four CBM blocks. The first commercial production of CBM started in July 2007. Thirty-eight $\mathrm{Mcm}$ were produced last year, bringing India into the fold of CBM producing countries. However, most of CBM produced is flared so far.

In 2007 the government decided however to restrain the market liberalisation trend with its gas utilisation policy (see section on policy and regulation). Furthermore, in early 2008 the Indian Finance Ministry issued a decision to scrap the seven-year tax holiday from payment of income tax on profits earned from production and sale of NELP natural gas output in the 2008/09 budget. Early 2009, this decision was cancelled by the Finance Minister for the 2009/10 budget for the last NELP round in order not to deter investments. There is no indication that the tax holiday will be granted for the upcoming $9^{\text {th }}$ round.

\section{The NELP VIII round}

In order to offset the decline of existing fields, meet growing gas demand and further incentivise E\&P, the Indian government launched an $8^{\text {th }}$ round of NELP in April 2009. The NELP VIII round offered 70 blocks ( 28 shallow water and 24 deepwater blocks). But the battle over KG-D6 gas in addition to the issue on the seven-year tax holiday has been deterring potential investors. The road shows for NELP VIII and CBM IV were therefore postponed by the Directorate General of Hydrocarbons, then relaunched in August 2009 with the deadline for bidding extended to October 2009. 
The results, announced mid-October 2009, show a limited success with only 76 bids for 36 out of $\mathbf{7 0}$ blocks, leaving half of the blocks unwanted. It is difficult to say to what extent the financial crisis, on the one hand, and the issues on prices, taxes and allocations on the other hand, resulted in this low number of bids. One should recognise that many licensing rounds in the world were similarly or even less successful. One criticism by investors related to the high percentage of Page | 24 blocks which were either relinquished or had already been offered in previous licensing rounds. The Government of India was nevertheless pleased to have attracted over USD 1.34 billion in minimum investment while it had attracted USD 1.7 billions in NELP VII for 45 blocks.

However, the dominance of the incumbent player ONGC could once again be noted: ONGC made 25 of the 36 bids and won 17 (14 as the operator), but many of them in partnership with other companies $^{9}$ and they did not get any CBM blocks. BHP Billiton bid for three blocks. Some private players such as Cairn India, Jubilant Energy and Deep Energy were successful, but RIL was notably absent. A new Indian player, Andhra Pradesh Gas Infrastructure Corp., appeared. The CBM licensing round went better: eight of the ten CBM blocks attracted 26 bids, notably from Essar Oil and Deep Energy.

\section{Which results after eight licensing rounds?}

The NELP policy aiming at increasing upstream investments by creating an investor-friendly climate was relatively successful and resulted in some major discoveries while allowing India to gain experience in the deepwater area. An increasing share of the natural gas production is now in the hands of private companies or private-public JVs. It has attracted many Indian private companies like RIL or more recently Andhra Pradesh Gas Infrastructure and has also attracted some foreign companies such as BHP Billiton, BG, Cairn Energy, Gazprom, Eni, Santos, Petrogas, although these companies still have a limited role. No major IOC has been participating in the bidding however, except BG, probably due to the government's policy of keeping relatively low prices on the domestic market.

After eight NELP rounds between 1999 and 2009, the area under exploration has increased more than six times - from $11 \%$ of the Indian Sedimentary Basin area before implementation of NELP to $68 \%$. But only $22 \%$ is well explored. A total of 326 blocks were offered by the government and 239 awarded (see Table 4), 72 of which were awarded to private companies and JVs. The number of production companies increased from 2 in 1990 to 12 in 2000 and 71 in 2009 and the number of producing basins increased from 3 in 1990 to 10 in 2009. Significant discoveries were made including Krishna Godavari in 2002 and the Cairn's discovery in Rajasthan. It also created an opening of acreages in ultra deepwater and frontiers areas.

9 ONGC's partners in these blocks are BG, OIL, Gujarat State Petroleum Corporation Ltd. (GSPC), GAIL, NTPC, Indian Oil Corporation Ltd. (IOC), and Andhra Pradesh Gas Infrastructure Corporation (APGIC). 
Table 4: Number of blocks in Pre-NELP and NELP rounds

\begin{tabular}{l|ccccccccc}
\hline NELP Round & $\begin{array}{c}\text { Pre } \\
\text { NELP }\end{array}$ & I & II & III & IV & V & VI & VII & VIII \\
\hline Offered & 379 & 48 & 25 & 27 & 24 & 20 & 55 & 57 & 70 \\
Awarded & 28 & 24 & 23 & 23 & 20 & 20 & 52 & 41 & 36 \\
To ONGC & $*$ & $8+11^{* *}$ & 16 & 13 & 14 & 8 & 25 & 19 & 17 \\
$\begin{array}{l}\text { Surrendered } \\
\text { by ONGC }\end{array}$ & & 4 & 14 & 1 & 1 & & & & \\
$\begin{array}{l}\text { ONGC as } \\
\text { operator }\end{array}$ & & 5 & 2 & 11 & 11 & 3 & 24 & 18 & 14 \\
\hline
\end{tabular}

* ONGC could take shares in licenses in all the Pre NELP blocks.

** Acquired majority interest in KG 98/2.

Source: ONGC (2009), ONGC (2010), press releases (2010).

A $9^{\text {th }}$ NELP Round is planned for the end of 2010, but this NELP round is likely to be the last one as the DGH has indicated that it is planning a gradual phase-out of the existing NELP licensing regime in favour of a new Open Acreage Licensing System (OALP) which could be introduced in 2011. However, there are still some issues to be tackled. This OALP system will enable bidders to bid for blocks on offer at any time of the year. Data on these blocks would be made available to the bidders through the National Data Repository (NDR), which would be in charge of collecting data on basins. As three quarters of basins are poorly or not explored at all, major work needs to be conducted. So far, progress on the NDR has been relatively slow.

Another crucial issue for the development of gas fields is pricing. While the increase of APM prices will incentivise PSUs to increase production levels, there are worries among investors about government decisions and interferences on pricing. This is illustrated by the battle over the allocation and price of the Krishna Godavari KG-D6 field.

\section{The Krishna Godavari KG-D6 field}

The major upstream development over the past few years is the start of the deepwater Krishna Godavari KG-D6 (block DWN-98/3) field operated by RIL. It was discovered in 2002, began producing in April 2009, and its potential is estimated at $337 \mathrm{bcm}$ (11.9 tcf) (DGH). RIL owns $90 \%$ and Canadian Niko Resources the remaining $10 \%$. Initially, production was expected to increase by an additional $10 \mathrm{Mcm} / \mathrm{d}$ each month up to $40 \mathrm{Mcm} / \mathrm{d}$ by July 2009 and to reach a plateau production of $80 \mathrm{Mcm} / \mathrm{d}$ only by 2011-12 - the equivalent of $29 \mathrm{bcm}$ of annual production, which would double India's current production. It was then expected to plateau and dwindle from 2017 to 2020 . However, potential production of $60 \mathrm{Mcm} / \mathrm{d}$ was reached in July 2009, although the field did not produce this amount of gas until early 2010 due to the lack of offtakers. Discussions on gas allocation are anticipating a production up to $90 \mathrm{Mcm} / \mathrm{d}$ $(33 \mathrm{bcm} / \mathrm{y})$, but recent trends seem to indicate that production would remain flat for another year and that the plateau level of $80 \mathrm{Mcm} / \mathrm{d}(29 \mathrm{bcm} / \mathrm{y})$ would be reached only in 2012 .

There are nevertheless two issues affecting KG-D6 field production: one relates to government decisions on the allocation and price of the gas, and the other to the legal dispute between the Ambani brothers, Mukesh Ambani who owns Reliance Industry (RIL) and Anil Ambani who owns Reliance Natural Resources (RNRL). It ended in May 2010 with the ruling of the Supreme Court. 


\section{The allocation of KG-D6 gas}

Gas is to be sold according to the Indian gas policy reflecting recent decisions on volumes and end-consumers. The gas produced during Phase I $(40 \mathrm{Mcm} / \mathrm{d})$ would therefore be allocated with the following priority and volumes.

Page | 26 - Fertiliser companies: $15 \mathrm{Mcm} / \mathrm{d}$

- Existing gas-fired power plants and plants to be commissioned before April 2010: $18 \mathrm{Mcm} / \mathrm{d}$

- LPG and Petrochemical plants: $3 \mathrm{Mcm} / \mathrm{d}$

- City gas distribution: $5 \mathrm{Mcm} / \mathrm{d}$.

Table 5: Allocation of KG-D6 gas

\begin{tabular}{l|ll}
\hline Sector & Firm allocation $\mathbf{( M c m} / \mathbf{d})$ & Interruptible allocation $(\mathbf{M c m} / \mathbf{d})$ \\
\hline Power plants & 31 & 12 \\
Fertilisers & 15 & \\
LPG and petrochemical & 3 & \\
City gas & 5 & 2 \\
Reliance Petroleum & 1.9 & \\
Oil companies & 6 & 6 \\
Captive power & & 10 \\
\hline
\end{tabular}

Source: Press releases (2010).

For the first $40 \mathrm{Mcm} / \mathrm{d}$, Reliance had initially contracts to sell gas to 15 fertiliser manufacturers, 19 power plants and 3 steel companies. It had also signed a sale and purchase agreement with GAIL for its LPG plant and with Indraprastha Gas for city gas for $0.3 \mathrm{Mcm} / \mathrm{d}$ to be increased to $0.5 \mathrm{Mcm} / \mathrm{d}$ by March 2010 and $2.1 \mathrm{Mcm} / \mathrm{d}$ within five years. During the first months of production in 2009, RIL had been forced to cap output, as close to one-fourth of the initial allocations were not taken. Customers, such as state power utility National Thermal Power Corporation (NTPC), Gail, Essar Power, and Ratnagiri Gas and Power, were not taking their allocated quantities or are taking very irregular quantities which could threaten the field's operations. Ratnagiri was not taking the $2.7 \mathrm{Mcm} / \mathrm{d}$ for which it signed up because it had contracted to buy regasified LNG from Petronet LNG through September 2009.

The decision on further allocations has been made by the EGoM in November 2009; RIL will increase output to $60 \mathrm{Mcm} / \mathrm{d}$ and sell another $30 \mathrm{Mcm} / \mathrm{d}$ on an interruptible basis. The final allocation of RIL's gas is given in Table 5. The dramatic increase of gas use in the power generation sector is a clear result of this (see section on demand). Fertilisers have been also switching from expensive oil products to gas. A slower than expected ramp-up of KG-D6 production would have an impact on customers allocated interruptible supplies.

\section{The Ambani brothers dispute}

In 2004, NTPC launched a tender for gas supplies and Reliance Industries, the main owner and operator of KG-D6 at that time, offered USD 2.34/MBtu for $12 \mathrm{Mcm} / \mathrm{d}$ for 17 years. Reliance Industries was then owned by Dhirubhai Ambani, Mukesh's and Anil's father. But in 2005, following his death, the company was split into RIL and RNRL. The conditions of the split were agreed in a Memorandum of Understanding (MOU) signed in June 2005 stating in particular that RIL would supply RNRL $28 \mathrm{Mcm} / \mathrm{d}$ for 17 years at the same price than originally offered to NTPC. 
In 2007, a price was agreed between RIL and the government under the PSC so that RIL was to sell gas at USD 4.2/MBtu for the first five years of production. This price level, often reported, reflects the calculation under a formula linking the price of gas to the price of oil:

$$
\mathrm{GP}=2.5+(\mathrm{OP}-25)^{\wedge} 0.15
$$

where OP is the annual average Brent crude price for the previous FY, with a cap of USD 60/bbl and a floor of USD 25/bbl. Since 2007, the annual Brent price has always been above USD 60.

Following that decision, Mukesh Ambani argued that RIL should sell gas at USD 4.2/MBtu instead of USD 2.34/MBtu to RNRL as well. But Anil's RNRL refused to pay this price on the basis of the MOU. This started a legal battle between RIL and RNRL. The legal proceedings revealed some agreements of the $\mathrm{MOU}$, notably one allowing RIL to use $25 \mathrm{Mcm} / \mathrm{d}$ for its refinery, petrochemical plants or sales to other users at a price determined by RIL.

Meanwhile, RIL and NTPC had already been in court since 2006, first because NTPC was accusing RIL of not fulfilling its supply obligations. After the agreement on a price level of USD 4.2/MBtu for KG gas, NTPC was also complaining about RIL's refusal to provide gas at USD 2.34/MBtu. This has put the two Ministries (Power and Petroleum and Natural Gas) in different positions.

In June 2009, the Bombay High Court decided that RIL should honour its engagement and supply $28 \mathrm{Mcm} / \mathrm{d}$ to RNRL at USD 2.34/MBtu. This is where the government stepped in July 2009, challenged the High Court's decision and stated that the pact between the two brothers should be null and void. Gas is national wealth, belongs to the state and the Ambani brothers have no right to argue about the price of national property. The government therefore asked the Supreme Court to break the judgment of the High court. This effectively happened in May 2010.

The dispute between the two brothers could have many consequences for the Indian market.

- The position of the state during this dispute has been closely scrutinised by foreign investors. It is not so much the issue on prices - a higher price would always be welcomed by potential upstream investors - than the fact that the government is intervening in commercial arrangements. As the Supreme Court supports the position of the Petroleum Ministry that gas is national wealth, then all companies having PSC with the government could see the conditions initially agreed under the PSC changed afterwards. This is against the initial aims of NELP - to give companies some marketing freedom.

- Selling gas at a lower price would have harmed RIL's revenues but also government revenues. Fields under the NELP are developed under a PSC between companies and the government. According to the PSC, it is intended that the company recover the investment in the first years, then each party is entitled to his part of the discovered gas. A lower price means that RIL would take longer to recover investments and this would reduce the state's revenues.

- Higher prices create uncertainties on the demand side. NTPC and RNRL as well as other power producers will have to pay a higher price than they thought. Power producers have been allocated $16 \mathrm{bcm}$, firm and interruptible. Meanwhile, customers, such as fertiliser companies, would have preferred a lower price to improve their competitiveness and also reduce the subsidies paid to the sector by the Indian government.

\section{What is the potential of unconventional gas?}

Historically, India has been focusing more on CBM but is now turning to shale gas. India had been organising CBM licensing rounds and the $4^{\text {th }}$ licensing round took place in 2009, but CBM production, which started in 2007, is very limited. CBM resources are estimated at $4.6 \mathrm{tcm}$ most 
of which are located in the North-East and North-West of the country. CBM is often sold as compressed natural gas (CNG), but also for power plants. A handful of Indian and foreign companies such ONGC, BP, RIL, Essar Oil, Arrow Energy, GAIL, and GEECL are active. So far, only 26 blocks representing $13600 \mathrm{~km}^{2}$ have been auctioned. During the last CBM round, seven CBM blocks were awarded, including two to Australian CBM player Arrow Energy and four to Essar

Page | 28 Oil. There were 26 bids for these blocks reflecting a higher interest than for conventional oil and gas resources. Arrow Energy will develop one with Oil India and the second with Tata Power; production is expected for 2014. Furthermore, Arrow Energy and ONGC signed a MOU on cooperation in early 2009.

Shale gas exploration is relatively new in India, but rapidly gaining the attention of industry players with ONGC launching a pilot project in 2011. MoPNG put DGH in charge of looking at shale gas potential and developing upstream regulation. It is considering offering acreages through a bidding process by 2011-12. RIL has moved ahead by acquiring acreages in the US shale play Marcellus, a way to gain experience to be transferred to Indian shale gas deposits. ONGC has not concluded any partnership with experienced players or tried to acquire experience in North America so far.

There remain a few key issues for the development of unconventional gas: lack of data as most of India remains underexplored (and unconventional gas has very often been considered as a long-term resource), pricing (including taxes and royalties) and regulatory policy, lack of domestic infrastructure and expertise.

\section{Outlook}

Despite the field KG-D6 coming on line and providing much needed supply to the Indian market, there are still major challenges for natural gas production in India. Existing fields are seeing their production declining and will need to be replaced; hence the efforts to bring new supplies to the market must be continued.

- Low level of exploration. Despite the recent drilling activities, India remains underexplored as noted earlier. NELP has nevertheless helped to improve data quality on potential resources. Not all NELP blocks have been assessed by drilling, and there are good opportunities to discover more oil and gas. There is still significant work to be conducted. This is why the Directorate General of Hydrocarbons (DGH) wants to create the National Data Repository (NDR) in order to gather E\&P data. The build-up and initial population phase of the NDR would take place in 2010 followed by an operational phase over 2011-15, during which the NDR will be populated with geo-scientific data (seismic data and well reports).

- Declining production from mature fields. Production from ONGC's existing fields, such as Panna Mukta Tapti and Bassein, is declining rapidly. Bassein, which still accounts for $45 \%$ of ONGC production after 20 years of operation, was forecast to flow $27.3 \mathrm{Mcm} / \mathrm{d}$ last year, falling to $22.75 \mathrm{Mcm} / \mathrm{d}$ in 2009/10, and $13.8 \mathrm{Mcm} / \mathrm{d}$ in 2011/12. Similar trends are observed at Mumbai High and other fields. Altogether this cumulative loss is roughly $20 \mathrm{Mcm} / \mathrm{d}$ $(7.3 \mathrm{bcm} / \mathrm{y})$ in about two years. ONGC have introduced Improved Oil Recovery and Enhanced Oil Recovery (IOR/EOR) schemes to address this issue and improve the oil and gas fields' production rates. The company invested USD 3.1 billion in 14 fields over 2000-09 to improve the recovery of oil fields from 27.5 to $33.1 \%$, and plans to invest USD 3.4 billion in seven 
fields over the coming years. ${ }^{10}$ They are also starting production from new gas fields, in particular in the Krishna Godavari Basin.

- Delays between discovery and production. These can be more than eight years for a number of small fields, which are still awaiting appraisal. The NELP resulted in a slight shortening of delay in bringing fields into production. It has indeed sped up the development of 20 finds in the Krishna Godavari Basin, discovered in 2002, with its largest one - block KGD6 operated by private companies - operational just 6.5 years after its discovery. There could be differences between the PSUs and the private firms in terms of delays; PSUs depend on government and administrative procedures (for example, ONGC needs government approval to buy rigs), and may not be able to offer the same salaries as in the private sector, while there is a shortage of qualified workforce.

- Lack of deepwater drilling. Persistent non-availability of rigs is impacting deepwater drilling. There has been a sharp drop in discoveries, while companies are unable to respect their work commitments. A three-year moratorium on exploration and appraisal has been in place on deepwater blocks from 2008 to end 2010. It has been ratified retrospectively for 30 deepwater blocks in July 2010; the blocks belong to ONGC, RIL and Eni.

- Lack of transport pipelines. There has been a lack of capital and investments in transmission connections. Interconnections between traditional consumption centres (located in the North and the centre of the country) and newly launched production centres, in particular the offshore Krishna Godavari Basin, need to be further developed. Meanwhile, new connections enabling gas to be delivered to consumers in all states, not only those in the highly industrialised West, are still missing. There is indeed a need to develop the transmission system to new demand centres.

- Gas flaring. Similar to the previous year, $1.03 \mathrm{bcm}$ of gas was flared in the overall production balance in FY 2009/10, the highest level seen over five years and a considerable improvement from the one third of gas production (around $5 \mathrm{bcm}$ ) flared in the early 1990s. This volume was reduced by $70 \%$ over ten years and has been diminishing since then. The percentage of gas flared to gross production from particular fields varied between $0.4 \%$ in Andhra Pradesh up to $6.8 \%$ in the Assam fields. It goes up to $83 \%$ for CBM fields. Flaring remains an important problem to be solved by a country facing gas scarcity.

Despite the shortcomings mentioned above and the limited success of the last NELP round, there are also some good prospects for increasing output from other new blocks:

- ONGC is working to slow the decline at its biggest gas field and to bring newer fields on line with enough success that its output may actually rise, rather than fall, over the next few years. The company slightly increased its gas output in FY 2009/10 to $23.1 \mathrm{bcm}$, up from $22.5 \mathrm{bcm}$ in FY 2008/09. By 2012/13, it hopes to see its output climb to $66 \mathrm{Mcm} / \mathrm{d}$ (or $25 \mathrm{bcm} / \mathrm{y})$. The recent increase in APM prices could also help ONGC increase its gas production in the upcoming years.

- ONGC made 21 field discoveries in 2009/10 (down from 28 in 2008/09) (ONGC, 2009) and plans to invest USD 5.3 billion in its two blocks next to KG-D6 with output target of $35 \mathrm{Mcm} / \mathrm{d}$ by $2013 .{ }^{11}$ It plans to tie up 10 discoveries in KG-DWN-98/2 - adjacent to D6 with the G-29, GS-4 and the Vashistha discoveries in shallow-water block KG-OS-DW4. Ten 
discoveries in KG-DWN-98/2 and three in the adjacent block together hold 6.37 tcf of inplace reserves.

- Gujarat State Petroleum Corporation (GSPC) has 3-4.6 tcf $(96-170 \mathrm{bcm})$ of gas reserves in its block Deendayal-West which the company wishes to see developed by 2011. In September 2009, the DGH approved the development of about $2 \mathrm{tcf}(71 \mathrm{bcm})$ of reserves at KG-8 Deendayal-West field. GSPC aims at a production of $11-12 \mathrm{Mcm} / \mathrm{d}$.

- ONGC has been investigating shale gas potential. An R\&D pilot project for exploration of shale gas in the Damodar Basin has been approved in March 2010. The potential for unconventional gas is thought to be important in India, which already produces CBM. One of the challenges for Indian NOCs will be to acquire some of the experience that unconventional gas players have gained in North America.

Table 6 gives an overview of the expected development of gas production for the upcoming years based on the eleventh five-year plan. Production was anticipated to grow from $30 \mathrm{bcm}$ in $2007 / 08$ to $44 \mathrm{bcm}$ in 2008/09, but fell short of that target in particular because the KG-D6 field started later than expected. Production was expected to increase to $69 \mathrm{bcm}$ in 2009/10, but failed to reach that level as production amounted to $46.5 \mathrm{bcm}$.

Although the IEA has a more conservative view on the long-term developments of domestic production, but foresees nevertheless a substantial increase between 2008 and 2015 based on the current upstream developments with domestic production reaching $60 \mathrm{bcm}$, twice as much as in 2008 (IEA, 2009).

Table 6: Domestic gas supply outlook - Projection by the working group of XI Five-Year Plan 2007-12 (bcm)

\begin{tabular}{l|ccccc}
\hline Source & $\mathbf{2 0 0 7 / 0 8}$ & $\mathbf{2 0 0 8 / 0 9}$ & $\mathbf{2 0 0 9 / 1 0}$ & $\mathbf{2 0 1 0 / 1 1}$ & $\mathbf{2 0 1 1 / 1 2}$ \\
\hline ONGC + OIL & 20.9 & 21.3 & 20.3 & 20.0 & 18.6 \\
$\begin{array}{l}\text { Pvt/JVs (as per DGH) } \\
\begin{array}{l}\text { Additional gas } \\
\text { anticipated }\end{array}\end{array}$ & 8.5 & 22.5 & 22.0 & 21.3 & 20.9 \\
$\begin{array}{l}\text { Total projected } \\
\text { production (optimistic) }\end{array}$ & 29.4 & 43.8 & 69.3 & 71.9 & 73.8 \\
\begin{tabular}{l} 
Actual production \\
\hline
\end{tabular} & 32.3 & 32.9 & 46.5 & & \\
\hline
\end{tabular}

Note: Additional gas resources come from upside potential from RIL and from discoveries of GSPCL.

Source: MoPNG, Report of the Working Group on Petroleum and Natural Gas Sector for the XI Plan (2007-12), November 2006. 


\section{Imports}

\section{Imports and contracts}

As India does not have any pipeline connection, all the gas currently imported is LNG.

Current operational LNG import capacity is $\mathbf{1 3 . 5} \mathrm{mtpa}$ (18 bcm). India joined the global LNG market in March 2004 when the Dahej LNG terminal went into operation. Petronet LNG Limited (PLL), a joint venture promoted by GAIL, IOCL, Bahrat Petroleum (BPCL), GDF Suez, the Asian Development Bank (ADB) and ONGC was formed to import LNG in order to meet the growing gas demand. PLL expanded this terminal from 5 to $10 \mathrm{mtpa}$ (6.8 to $13.6 \mathrm{bcm}$ ) in early 2009. The second LNG terminal is the Shell and Total $3.5 \mathrm{mtpa}(4.8 \mathrm{bcm})$ terminal located in Hazira, which was commissioned in April 2005. ${ }^{12}$ Both are located on the western coast and could be further expanded to 15 and $10 \mathrm{mtpa}$ respectively. The third terminal, the DabholRatnagiri LNG terminal, is expected to become operational in $\mathbf{2 0 1 0}$, after many delays. It has a total capacity of $5.5 \mathrm{mtpa}(7.5 \mathrm{bcm})$, with about $2.9 \mathrm{mtpa}(3.9 \mathrm{bcm})$ available for merchant sales. The commissioning date was delayed from mid-April 2009 to an unspecified date in 2010 because of the monsoon season, breakwater facilities and construction costs, and no new commissioning date has been given since. It would first only operate at a capacity of $1 \mathrm{mtpa}$ $(1.4 \mathrm{bcm})$ and ramp up to planned capacity gradually.

LNG import capacity could be extended to over $80 \mathrm{bcm}$ ( $63 \mathrm{mtpa}$ ), if all planned terminals come to fruition (see Table 8 below). However, those investments are likely to face some difficulties and delays related to lack of capital and difficulties to secure new supplies: only seven LNG liquefaction plants have taken a Final Investment Decision (FID) since mid-2005. The Gorgon LNG facility in Australia, which took the FID in 2009, will sell $1.5 \mathrm{mtpa}$ to the Indian gas market. However, the Indian gas market might be less ready to accept LNG prices at the same level as Japan, Korea or even China whose regasification capacity is increasing rapidly.

In 2009/10, India imported 12.3 bcm of LNG from Qatar (under a long-term contract), Australia, Trinidad and Tobago, and Russia as well as from a few other countries. LNG was imported at the two operational terminals. LNG imports have been growing as can be seen in Table 7. This trend has continued in 2009/10 with LNG imports rising from $11.6 \mathrm{bcm}$ in 2008/09. The surplus of LNG, driven by lower demand in the traditional LNG importers such as Japan and Korea and the collapse of spot prices, ${ }^{13}$ has enabled India to import LNG at prices around USD 4-5/MBtu. For example, Petronet bought spot cargoes from North West Shelf (Australia) in 2009. Other factors also came into play:

- The increase of naphtha prices

- falling production of the mature fields such as Bombay High

- problems with securing the domestic supplies from KG-D6 field.

12 The capacity was initially $2.7 \mathrm{mtpa}$ but was expanded to $3.5 \mathrm{mtpa}$ in 2008.

13 NBP price has fallen from USD 13/MBtu in September 2008 to USD 3-4/MBtu during Q3 2009. 
Table 7: India LNG imports by country (bcm)

\begin{tabular}{|c|c|c|c|c|c|c|}
\hline & $2004 / 05$ & $2005 / 06$ & $2006 / 07$ & $2007 / 08$ & $2008 / 09$ & $2009 / 10$ \\
\hline Abu Dhabi & & & 0.09 & 0.08 & 0.13 & 0.16 \\
\hline Australia & & & 0.09 & & 0.16 & 1.11 \\
\hline Indonesia & & & & & & 0.08 \\
\hline Malaysia & & & 0.09 & 0.09 & 0.08 & 0.25 \\
\hline Oman & & & 0.27 & 0.27 & 0.41 & 0.35 \\
\hline Qatar & 3.49 & 6.98 & 8.24 & 9.43 & 8.34 & 7.95 \\
\hline Algeria & & & 0.09 & 0.55 & 0.53 & 0.16 \\
\hline Nigeria & & & 0.09 & 0.77 & 0.38 & 0.32 \\
\hline$T \& T$ & & & & 0.24 & 0.23 & 0.68 \\
\hline Egypt & & & 0.62 & 0.09 & 0.24 & 0.33 \\
\hline E. Guinea & & & & & 0.42 & 0.25 \\
\hline Norway & & & & & 0.08 & \\
\hline Russia & & & & & & 0.68 \\
\hline Others & & & & & 0.17 & \\
\hline Total & 3.49 & 6.98 & 9.59 & 11.52 & 11.16 & 12.31 \\
\hline
\end{tabular}

Source: IEA, Natural Gas Information 2010.

Until 2009, India had only one long-term LNG contract signed to supply the Dahej terminal for $5 \mathrm{mtpa}(6.7 \mathrm{bcm})$, as the second operational terminal in Hazira operates on the merchant model. The long-term contract from 2004 with Qatar's RasGas stated that Dahej's operator, Petronet LNG, was based on a fixed price of USD 2.53/MBtu f.o.b. for $5 \mathrm{mtpa}$ for the first five years. Since January 2009, this price increased to USD 3.12/MBtu. Volumes under this contract have risen to $7.5 \mathrm{mtpa}(10 \mathrm{bcm})$ in Q4 2009, due to the extension of the terminal's capacity.

Petronet tried to acquire additional LNG for Dabhol from Qatar and there have been intense discussions on further volumes in 2006-07 due to a price disagreement: Qatar offered USD 10/MBtu while Petronet did not want more than USD 5.5/MBtu. They agreed on a shortterm contract of $1.2 \mathrm{mtpa}$ from March 2007 to June 2009. In 2010, Qatar announced that these supplies will be boosted to $11.5 \mathrm{mtpa}$ by 2014 . This could start as soon as 2011 with an additional $1 \mathrm{mtpa}$, increasing to $2.5 \mathrm{mtpa}$ by 2012 and $4 \mathrm{mtpa}$ by 2014 .

On 8 May 2009, Petronet LNG finalised talks concerning the purchase of $1.5 \mathrm{mtpa}(2 \mathrm{bcm})$ of LNG for 20 years from ExxonMobil's planned output from the Gorgon LNG plant in Australia, expected to start operating in 2014. This puts total contracted LNG supplies to $18 \mathrm{bcm}$ as of 2014, two thirds of the LNG capacity which will be online at that time. ${ }^{14}$ The Australian supplies would primarily be sent to the Kochi terminal, which is scheduled to become operational by 2012. Gorgon's sponsors took the FID in September 2009. Petronet has taken a lower share in Gorgon than that mentioned in early 2008 - $3.75 \mathrm{mtpa}$. It seems that Petronet has acquired more confidence with the start of the KG field and the fact that ample LNG supplies are available. With the current gas surplus, the market has currently turned into a buyers' market, and Petronet is currently looking at potential cheaper LNG alternatives priced at a spot price level which is currently half that of oil-linked price. This strategy is fine as long as there is no tightening of the supply and demand balance on global gas markets or even in the Pacific Basin, which is expected to tighten more quickly than Atlantic markets. It will certainly be 
more difficult to attract cheap spot LNG once markets tighten. Indian companies are therefore looking for additional long-term LNG supplies. Some Indian customers have recently shown interest in medium- to long-term contracts at Hazira, probably as the result of difficulties securing domestic gas supplies and the drop of international spot prices. Petronet is in discussion with several companies to increase future imports of LNG under long-term contracts. It has been in discussion with Algeria (Sonatrach) since 2007 over a $1.25 \mathrm{mtpa} 25$-year contract. Petronet is interested in another project in Australia - the Kimberley hub for the Browse Basin development. It also wants to acquire a stake in the Niugini project (Papua New Guinea) from Canada's Inter Oil, which seeks to sell a $20 \%$ of this project.

Since 2006, India has been importing many spot cargoes, not only to Hazira, but also to Dahej. In 2009, India has become a destination of choice for many Pacific and Middle East exporters due to increasing demand, proximity and netbacks relatively comparable, if not better, to the United States or the United Kingdom. Since the start-up of Sakhalin, Hazira and Dahej have received several Russian cargoes as Russia tries to keep exports East of Suez. Petronet and GSPC bought five and one spot cargoes respectively from NWS in Australia; cargoes from Indonesian Tangguh plant have also been diverted to India. Due to proximity, some Yemeni cargoes may go to India instead of the United States if Henry Hub prices stay around USD 5/MBtu.

Nevertheless, since KG-D6 reached an output of $60 \mathrm{Mcm} / \mathrm{d}$ in November 2009, only one spot cargo per month has been arriving to India. Increased domestic production has moderated the appetite for spot LNG and we are seeing a "wait-and-see" approach during 2010: market players wait to see how much appetite there is still for gas once KG-D6 produces at its maximum level. This also depends on the price of spot cargoes. Petronet has stopped importing spot cargoes since December 2009, but has been starting to import in August 2010.

\section{Import infrastructure}

IEA's forecasts on demand and domestic production imply a supply gap of $18 \mathrm{bcm}$ by $\mathbf{2 0 1 5}$, increasing to $28 \mathrm{bcm}$ by 2020 and $52 \mathrm{bcm}$ by 2030 . In any case, LNG seems set to remain the first source of imports for India for at least the five years to come. So far, India does not import by pipeline. While several projects are under consideration, they are still far from even taking Final Investment Decision.

\section{LNG regasification terminals projects - the preferred option}

India's import capacity consists of LNG regasification terminals with a current capacity of $13.5 \mathrm{mtpa}(18 \mathrm{bcm})$. This capacity is expected to increase based on projects currently under construction and in planning. Only the $5.5 \mathrm{mtpa}$ Dabhol and $2.5 \mathrm{mtpa}$ Kochi are under construction with a start in 2010 and 2012 respectively. Meanwhile, up to $40 \mathrm{mtpa}$ (54 bcm) of capacity is planned (see Table 8). Both existing LNG terminals are planned for expansion. It is unlikely that all these LNG terminals will come online; so far only the Dabhol and Kochi can realistically come online before 2015 as the market faces an increase of domestic production and uncertainties on global prices. It is likely that many users will try to secure cheaper domestic gas before potentially looking at LNG. But some are likely to be built due to India's growing appetite for gas. 
Table 8: India LNG terminals, existing, under construction and planned

\begin{tabular}{|c|c|c|c|c|c|}
\hline & Terminal & Partners & Capacity & Supply source & $\begin{array}{l}\text { Start- } \\
\text { up date }\end{array}$ \\
\hline & \multicolumn{5}{|c|}{$\begin{array}{r}\text { Existing } \\
\end{array}$} \\
\hline \multirow[t]{16}{*}{ Page | 34} & Dahej & $\begin{array}{l}\text { Petronet LNG (GAIL, ONGC, Indian } \\
\text { Oil and BPLC (each 12.5\%), GDF } \\
\text { Suez (10\%), ADB (5.2\%) and private } \\
\text { shareholders ( } 34.8 \%) \text { ) }\end{array}$ & $10 \mathrm{mtpa}$ & Qatar - long term (7.5 mtpa) & $\begin{array}{l}\text { March } \\
2004\end{array}$ \\
\hline & Hazira & Shell (operator, 74\%), Total (26\%) & $3.5 \mathrm{mtpa}$ & Merchant model & $\begin{array}{l}\text { April } \\
2005\end{array}$ \\
\hline & \multicolumn{5}{|c|}{ Under construction } \\
\hline & Dabhol & $\begin{array}{l}\text { NTPC, GAIL, Indian banks }{ }^{15}(28.3 \% \\
\text { each) and the Maharashtra state } \\
\text { Electricity Board (15\%). }\end{array}$ & $\begin{array}{l}5.5 \text { mtpa } \\
\text { (1 mtpa } \\
\text { initially) }\end{array}$ & $\begin{array}{l}\text { Possible: Algeria, Qatar, Australia, } \\
\text { Oman and Abu Dhabi }\end{array}$ & 2010 \\
\hline & Kochi & Petronet LNG & $2.5 \mathrm{mtpa}$ & $\begin{array}{l}1.5 \text { mtpa for } 20 \text { years from } \\
\text { ExxonMobil's Gorgon, Australia } \\
\text { (2014-15). Possibly Qatar, Papua } \\
\text { New Guinea }\end{array}$ & 2012 \\
\hline & \multicolumn{5}{|c|}{ Planned } \\
\hline & Dahej exp & Petronet LNG & $2.5 \mathrm{mtpa}$ & n.a. & 2012 \\
\hline & Hazira exp & Shell, Total & $6.5 \mathrm{mtpa}$ & n.a. & n.a. \\
\hline & Kochi exp & Petronet LNG & $2.5 \mathrm{mtpa}$ & n.a. & 2014. \\
\hline & Mundra Port & GSPC (75\%), Adani Group (25\%) ${ }^{16}$ & $6.5 \mathrm{mtpa}$ & n.a. & 2012 \\
\hline & Mangalore & ONGC & $5 \mathrm{mtpa}$ & Possibly Oman, Qatar, Africa & 2012 \\
\hline & Pipapav Port & $\begin{array}{l}\text { EssarGroup, Swan Energy, possibly } \\
\text { GSPC Gujarat Pipavav Port Ltd. } \\
\text { Intends to become a partner }\end{array}$ & $5 \mathrm{mtpa}$ & n.a. & 2013 \\
\hline & Ennore & TIDCO, Oillndia & $5 \mathrm{mtpa}$ & n.a. & 2015 \\
\hline & Haldia & Spice Energy & $2.5 \mathrm{mtpa}$ & Indonesia & 2011 \\
\hline & Kandla & $\begin{array}{l}\text { Kandla Port Trust, possibly private } \\
\text { companies }\end{array}$ & 2 mtpa & n.a. & n.a. \\
\hline & Mangalore & MMTC, (Bharat Petroleum) & $2.5 \mathrm{mtpa}$ & n.a. & 2015 \\
\hline
\end{tabular}

Note: this data represents companies' expectations regarding online dates and not the IEA view.

Source: IEA, company reports, press releases.

The latest developments seem to confirm the Indian LNG potential's expansion course. In particular, securing LNG for Kochi from Gorgon is a decisive step to advance the project. Corporation of Chinese Taipei was awarded the onshore engineering, procurement and construction (EPC) job for the terminal. Construction is said to take 22 months, and Kochi is now scheduled to start operations in 2012.

As mentioned earlier, constraints in domestic pipeline infrastructure are important for future LNG regasification terminals. For example, gas from the Dahej terminal flows through Gail's HVJ pipeline as does production from the Gujarat coast. As a result, little spare capacity is available in this pipeline. This problem was particularly acute during summer of 2009, when demand from the power generation sector in the region of New Delhi was exceptionally high due to the late arrival of the monsoon rains.

15 The bank consortium comprises IDBI Ltd. (10.65\% of the total shares), State Bank of India (8.67\%), ICICI Bank (7.14\%) and Canara Bank (1.87\%).

16 GSPC is expected to sell $25 \%$ to a strategic partner, reducing its share to $50 \%$, but no potential partners have been named. 


\section{Gas pipelines projects - a distant prospect}

With the new LNG terminals starting over the upcoming three years and many LNG planned terminals added to the increase of domestic production, pipeline routes appear as a more distant option.

Two pipeline projects have been under consideration to bring pipeline gas to India for many years: the Iran-Pakistan-India (IPI) from Iran, and the Turkmenistan-Afghanistan-Pakistan-India (TAPI) from Turkmenistan. A third one from Myanmar seems to have lost momentum.

\section{The IPI pipeline project}

The Iran-Pakistan-India pipeline project was launched in the 1990s. After long years of negotiations between the neighbouring countries concerning pricing and delivery terms, from which India has virtually withdrawn since the terror attacks in Mumbai in November 2008, Iran and Pakistan finally agreed on 5 June 2009 to develop an Iran-Pakistan (IP) pipeline, moving ahead with the first part of what is still intended to be a trilateral project, the so-called "Peace Pipeline". One week before the first round of the Iranian presidential elections in 2009, Iran and Pakistan signed an agreement for Iran to supply Pakistan with $7.5 \mathrm{bcm} / \mathrm{y}$ for 25 years, with an extension of an additional five years in case of mutual agreement. Both countries expressed their interest in a future Indian participation. In March 2010, Pakistan and Iran signed a Head of Agreement to build a $7.5 \mathrm{bcm}$ pipeline by 2015 .

There are nevertheless several issues that complicate the completion of the pipeline and India's participation, notably the development of Iran's resources, as well as pricing and geopolitical issues.

- Firstly, despite Iran's huge gas resources estimated at 29 tcm (as of end 2009), the country is a net gas importer as demand is increasing more rapidly than production. Demand has increased from $96 \mathrm{bcm}$ in 2005 to $140 \mathrm{bcm}$ in 2009 according to IEA's estimates, making it the second non-OECD market behind Russia and before China. The huge and increasing requirements for reinjection, in addition to a booming domestic market, require substantial investments in exploration and production, but Iran is suffering from a poor investment climate due to international political tensions and the most recent developments make this unlikely to change in the short term. Besides its huge domestic requirements, Iran is engaged in several export projects ranging from LNG to pipeline to the East (Pakistan and India) and the West (Turkey and Europe).

- Iran linked the price of gas in the pipeline to a gas price formula similar to that for Japanese LNG based on Japanese Crude Cocktail (JCC) price. However, the USD 0.49/MBtu fee demanded by Pakistan combined with the transportation tariff of USD 1.57/MBtu would mean that the cost of gas at the Indian border would be close to USD 7/MBtu, almost USD 2.50/MBtu more than India was willing to spend and more than recent spot prices. Negotiations have continued over transit fees for two years without success. ${ }^{17}$

- Geopolitical issues hampering the pipeline extension to India are diverse: they range from concerns about a safe transit through Baluchistan to the tense international relations. One important issue for India is represented by the history of mistrust and recent conflicts with Pakistan, in particular stability and security concerns regarding the Baluchistan province in

17 Pakistan has also offered India the alternative option to buy gas at the Pakistan-India border from Pakistan and let Pakistan and Iran deal with the pipeline. However, Indian sources pointed out that this could put India in a critical situation for its nuclear relations with the United States. 
Pakistan, through which a portion of the pipeline is planned. India would need strong domestic support to be dependent on Pakistan by accepting it as a transit route for part of its energy imports.

\section{The Turkmenistan-Afghanistan-Pakistan-India pipeline (TAPI)}

This proposed pipeline along a $1680 \mathrm{~km}$ route aims to deliver $30 \mathrm{bcm} / \mathrm{y}$ of gas to consumers in Afghanistan, Pakistan and India. Capital cost is estimated at USD 8 billion. In April 2009, the governments of the four countries signed a framework agreement to construct TAPI. However, the project has been pending for more than 10 years. It is backed by the United States, but from the Indian perspective, the security situation in Afghanistan makes it a more distant prospect than the IPI pipeline. Security of the TAPI route through Afghanistan is an impediment, although, in 2008, the Afghan government made several pledges to address these concerns.

The framework agreement states that the TAPI pipeline would be built by a consortium of national oil companies from the four nations. The draft Gas Pipeline Framework Agreement provides for payment of transit fees to Afghanistan and Pakistan for allowing usage of their territories for passage of the pipeline, on internationally accepted cost-of-service based tariff methodology. The two nations would be entitled to a transit fee based on gas exiting their territories and not for the natural gas consumed, lost or disposed of within their territories. The IP pipeline would undermine the participation of Pakistan to the TAPI pipeline. Furthermore, Pakistan expressed its interest to source Turkmen gas via Iran through the IP pipeline. This would require a new pipeline to be built to connect Turkmenistan to Pakistan but also to agree on pricing issues.

ADB has conducted feasibility studies and provided technical assistance for the project in the past. Any progress in the pipeline would likely involve ADB assistance as well; however ADB did not confirm its intention to fund $25 \%$ of the $1680 \mathrm{~km}$ TAPI pipeline project that has been considered by Pakistan.

Another question concerns resources. Although reserves have been re-evaluated upwards in 2008 due to the South Yolatan field, Turkmenistan has committed significant volumes to Russia, as well as to China under long-term contracts, which exceed by far its current production. Furthermore, Turkmen gas production has often missed the official optimistic targets. Turkmenistan is also planning to increase exports to Iran by expanding the existing pipeline and building another one. Europe is also looking at Turkmen gas although the issue is held back by the lack of a Trans-Caspian pipeline.

\section{The Myanmar-India pipeline}

A $1575 \mathrm{~km}$-long pipeline connecting the Shwe field to the A-1 block in Myanmar, in which both ONGC Videsh and GAIL own a stake ( $20 \%$ and $10 \%$ respectively), was considered to bring gas to India, passing through Bangladesh. The consortium of blocks A1 and A3 had recently declared a total discovery of GIIP of $5.35 \mathrm{tcf}$ of gas. However, not much progress has happened on this front recently while an export pipeline to China has started construction in mid 2010. 


\section{Demand}

\section{Current consumption and forecasts}

According to the MoPNG, gas use in India amounted to $59 \mathrm{bcm}$ in FY 2009/10, up from $43 \mathrm{bcm}$ in FY 2008/09; energy use amounted to $61 \%$ compared to $39 \%$ used for non-energy purposes (see Table 9). Before the start of Krishna-Godavari in April 2009, consumption was supply constrained and demand for gas could easily have been $\mathbf{3 0 ~ b c m}$ higher. Indeed, it is important to make a clear distinction between potential demand and actual consumption as these numbers widely differ. In 2007, unmet demand was estimated at $35 \mathrm{bcm} .{ }^{18}$ Demand has been constrained by the lack of supply as domestic production and LNG imports, even at the recent higher supply rates, were insufficient to meet potential demand. The IEA presented two longterm scenarios in the WEO issued in November 2009: a Reference Scenario and a 450 Scenario. The first scenario can be described as business-as-usual, while the second tries to limit the global temperature increase to $2^{\circ} \mathrm{C}$. In its Reference Scenario, the IEA expects Indian gas demand to increase to $94 \mathrm{bcm}$ by 2020 and to $132 \mathrm{bcm}$ by 2030, driven by the industrial and power generation sectors. This means an annual increase of $5.4 \%$ - one of the highest in the world. ${ }^{19}$ In the 450 Scenario, demand by 2020 would be slightly lower $(89 \mathrm{bcm})$, but by 2030 would almost remain at the same level as in the Reference Scenario - $132 \mathrm{bcm}$ - as gas would be needed to displace coal.

The latest available Indian demand forecasts for the $11^{\text {th }}$ five-year plan (2007-12) show gas demand increasing by between $37 \%$ and $58 \%$ over that period and the power sector being the main driver for incremental gas demand (see Table 10). However, these gas demand forecasts are the maximum demand levels that could be reached without any supply or price constraints, rather than likely actual use. They do not take into account any constraints in the power generation sector and in fertiliser production. Total demand for 2008/09 was estimated at $72 \mathrm{bcm}, 30 \mathrm{bcm}$ higher than actual consumption, while demand for 2009/10 was to reach $81 \mathrm{bcm}$ by $2009 / 10$ compared to $59 \mathrm{bcm}$. Unmet demand rests in the power sector and the industrial sector (around $40 \%$ of unmet demand each) with fertiliser production accounting for the rest. According to these forecasts, demand would reach between $89 \mathrm{bcm}$ and $103 \mathrm{bcm}$ by 2011/12. The share from the different sectors would remain almost constant in the high demand case scenario (Scenario I in Table 9 below, given only for 2011/12) but see a quite substantial reduction of the power sector from $45 \%$ to $36 \%$ in the low demand case scenario. The IEA does not expect demand levels reaching $90 \mathrm{bcm}$ much before 2015-20, reflecting this difference between maximum potential demand and actual use. 
Table 9: India's gas use (Mcm)

\begin{tabular}{|c|c|c|c|c|c|}
\hline & $2004 / 05$ & 2005/06 & 2006/07 & $2007 / 08$ & $2008 / 09$ \\
\hline \multicolumn{6}{|l|}{ Energy purposes } \\
\hline Power generation & 12099 & 11878 & 11963 & 12037 & 12603 \\
\hline Industrial fuel & 3569 & 3780 & 3205 & 3324 & 5912 \\
\hline Tea plantation & 142 & 151 & 170 & 160 & 154 \\
\hline Domestic fuel & 343 & 75 & 443 & 39 & 102 \\
\hline Captive use/LPG shrinkage & 4944 & 5048 & 5034 & 5618 & 5706 \\
\hline Others & 231 & 1120 & 40 & 1258 & 1535 \\
\hline \multicolumn{6}{|l|}{ Non-energy purposes } \\
\hline Fertiliser & 8173 & 7762 & 8497 & 9822 & 9082 \\
\hline Petro-chemicals & 1236 & 1175 & 1377 & 1432 & 1105 \\
\hline Others & 38 & 36 & 639 & 638 & 6761 \\
\hline TOTAL & 30775 & 31025 & 31368 & 34328 & 42960 \\
\hline
\end{tabular}

Source: Ministry of Petroleum and Natural Gas of India.

Table 10: Gas demand projection (bcm)

\begin{tabular}{|c|c|c|c|c|c|c|}
\hline \multirow[t]{2}{*}{ Sector } & \multirow{2}{*}{$\begin{array}{c}2007 / 08 \\
1\end{array}$} & \multirow{2}{*}{$\begin{array}{c}2008 / 09 \\
I\end{array}$} & \multirow{2}{*}{$\begin{array}{c}2009 / 10 \\
I\end{array}$} & \multirow{2}{*}{$\begin{array}{c}2010 / 11 \\
\text { I }\end{array}$} & \multicolumn{2}{|c|}{ 2011/12 } \\
\hline & & & & & 1 & II \\
\hline Power & 29.2 & 33.2 & 37.6 & 41.6 & 46.4 & 32.5 \\
\hline Fertiliser & 15.0 & 15.7 & 19.0 & 28.8 & 28.8 & 28.8 \\
\hline City Gas/Industrial & 9.9 & 10.6 & 11.3 & 12.4 & 13.1 & 13.1 \\
\hline Sponge Iron & 2.2 & 2.2 & 2.6 & 2.6 & 2.9 & 2.9 \\
\hline Other (Petrochem/ & & & & & & \\
\hline $\begin{array}{l}\text { Refinery/Internal } \\
\text { Consumption) }\end{array}$ & 9.1 & 9.9 & 10.6 & 11.3 & 12.0 & 12.0 \\
\hline Total (Mcm/d) & 179 & 196 & 222 & 265 & 283 & 245 \\
\hline Total (bcm) & 65 & 72 & 81 & 97 & 103 & 89 \\
\hline
\end{tabular}

Source: India Oil \& Gas.

Indian GDP growth dropped to $5.7 \%$ in 2009 , well below the previous years' levels according to the IMF's World Economic Outlook from July 2010. ${ }^{20}$ The IMF expects Indian GDP to grow back to $9.4 \%$ and $8.4 \%$ in 2010 and 2011 respectively.

\section{Demand analysis by sector}

\section{Power generation}

Gas demand in the power generation sector requires looking at the whole power sector in India. Future gas use in this sector will depend on three factors: electricity demand, gas availability and competitiveness of gas-fired plants versus coal-fired plants.

Analysing the challenges of India's power sector is not the aim of this Working Paper, but the main issues concern lack of access to electricity for many people, electricity shortages both on an annual and a peak basis, and the need to attract investments in generation, transmission and

20 IMF data are based on calendar year, and can be different from India's figures based on the fiscal year. 
distribution in order to sustain economic growth. India's impressive economic growth over the past decade has resulted in booming demand for electricity, but energy poverty represents a tremendous challenge. In 2001, $44 \%$ of households did not have access to electricity.

In order to provide electricity to more people, major investments will be required. Electricity shortages have been typically around 7\% during the 1996-2006 period and the peak electricity shortage up to $14 \%$. The current capacity as of July 2010 amounts to $163.7 \mathrm{GW}$, according to the Central Electricity Authority (CEA), with gas representing $11 \%$ versus $52 \%$ for coal and $24 \%$ for hydro (see Figure 3). There are now 17.4 GW of gas-fired plants, two thirds of which have been installed since 1995. The IEA estimates that India's generation capacity will increase almost fourfold between 2009 and 2030 to reach $571 \mathrm{GW}$ with gas-fired capacity increasing from $17 \mathrm{GW}$ to $65 \mathrm{GW}$. Electricity generated by gas-fired plants is expected to increase to $299 \mathrm{TWh}$ by 2030 (IEA, 2009). The Ministry of Power and the CEA estimated that $78.7 \mathrm{GW}$ would be needed between 2007 and 2012 in order to fully meet electricity and peak demand by 2012. This will also require significant investments in both the transmission and the distribution segments.

Gas has benefited from the shortages of electricity and domestic coal which resulted in higher electricity prices, helping gas to be used base load even with non-APM gas. Gas availability has been a constant problem over the 2000-09 period, but the situation has only started to improve since mid-2009. Previously, gas-fired plants were utilised at around $50 \%$ of their capacity. In fact, many gas-fired plants had been running on naphtha or remained idle when naphtha was too expensive due to the limited availability of gas. The CEA estimated that the shortfall of gas to the power generation sector over the period 2000-08 was between 18 and $28 \mathrm{Mcm} / \mathrm{d}(6.6$ and $10.2 \mathrm{bcm}$ ). In 2008, the $220 \mathrm{MW}$ Jegurupadu CCGT was unable to generate due to shortages of gas while $909 \mathrm{MW}$ were pending commissioning for the same reason. The year 2009 has seen a considerable improvement with KG-D6 coming on line. Since then, total thermal generation has been close to targets. The gas-fired plant load factor (PLF) has increased from $57 \%$ in January 2009 to 66\% in April 2009 to $77 \%$ in April 2010. PLF in 2009/10 was around 10\% higher than the same period one year earlier. Meanwhile, the PLF of lignite and coal plants declined due to shortages of domestic coal and failure to secure imports.

We can expect gas supply constraints to be less of an issue in the power generation sector over the coming years; the main issue will be the competitiveness of gas-fired plants.

Figure 3: Generation capacity in India (July 2010) (GW)

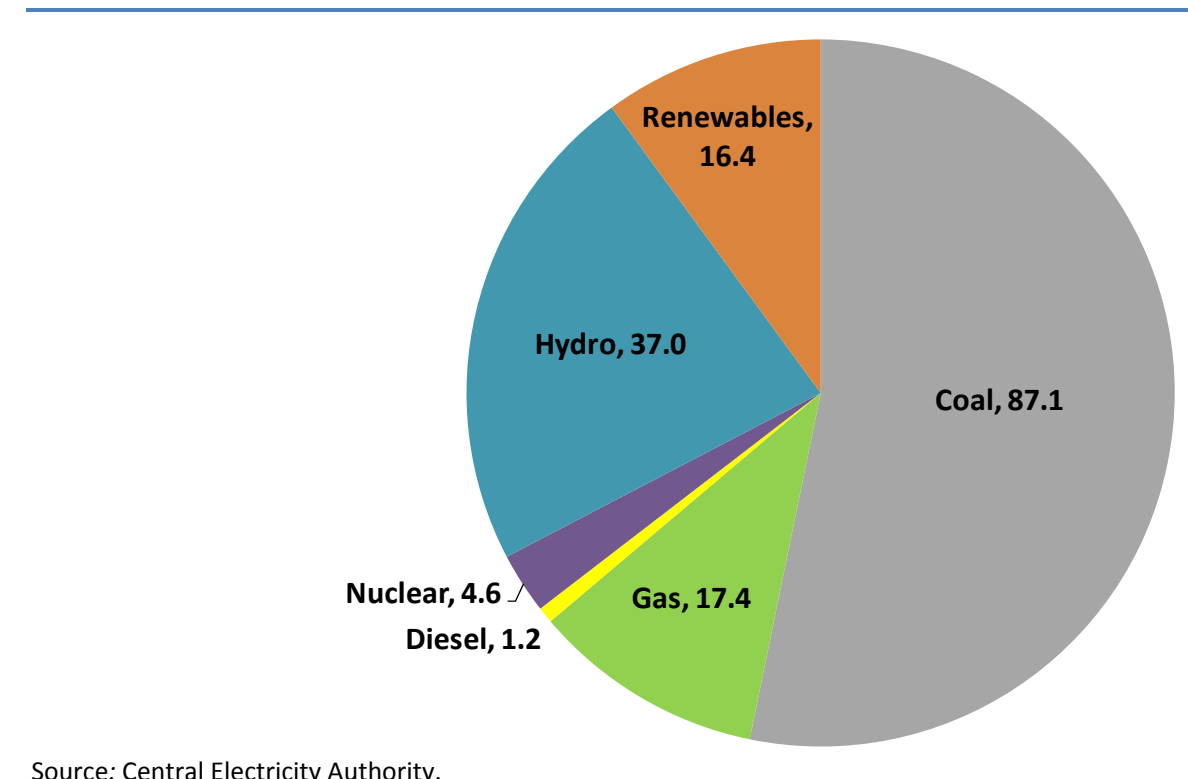

Source: Central Electricity Authority. 
The third issue is the competitiveness of gas versus coal as natural gas competes with coal for base-load generation. This will determine whether gas is used for base load or to meet peak demand requirements. Future demand from gas-fired plants depends strongly on the evolution of gas prices and the path of the reforms in the coal sector. The government plans to liberalise the domestic coal sector in order to improve the efficiency and attract new investments. In Page | 40 most cases, it will be difficult for gas to compete against domestic coal, especially if coal-fired plants are located near mines. However, it has to be observed that most coal reserves are located in the eastern states, where generation already exceeds consumption by far. More coalfired generation would require coal to be transported over long distances or imported, or electricity transmission lines to be built between regions: these options have a cost. Imported coal could be attractive, especially at the large power plants proposed at coastal locations. Furthermore, the policy aimed at reducing air pollution from coal use (including sulphur dioxide) could give an advantage to gas. Finally, the expected rationalisation of the Indian electricity grid could provide an opportunity for natural gas to play a larger role to meet peak demand.

We have compared gas-fired plants to coal-fired plants in India, taking two approaches.

The first approach is to look at short-run marginal costs (SRMC) for existing plants:

- There are five different cases; the only variable for the gas-fired plants is the price. The analysis is based on $250 \mathrm{MW}$ gas-fired plants, with a $46 \%$ efficiency. This is a relatively high efficiency, reflecting plants installed over the past decade. Older plants would be less efficient. As we have mentioned before, many gas-fired plants used to have access to APM gas at USD 1.8/MBtu, but APM prices have been recently increased to the level of KG-D6 gas price. Depending on the plant location, a transport cost through the EWPL and GAIL's network needs to be added. The five cases are: APM gas (before May 2010 to highlight the difference with the new price) transported through the HVJ line, KG-D6 gas consumed in the eastern region, KG-D6 gas consumed in the north-western region, LNG imports from Qatar and spot LNG imports both consumed in the north-western region (see section on prices). For spot LNG, a price of USD 8/MBtu delivered has been assumed, which may look expensive for the SRMC taking into account the current market conditions (Henry Hub prices are around USD 5/MBtu as of July 2010), but would reflect higher prices for the generating costs with markets tightening around the middle of the decade.

- Gas-fired plants have been compared to four coal-fired plants, three using domestic coal and one using imported coal. Plants using domestic coal have a $32 \%$ efficiency versus $37 \%$ for imported coal. Domestic coal is based on Grade E coal prices as published by Coal India, and is burned either at the mine mouth, or transported $700 \mathrm{~km}$ or $1500 \mathrm{~km} ;{ }^{21} 700 \mathrm{~km}$ is close to the average historical transport distance for coal, while $1500 \mathrm{~km}$ reflects longer distance between the eastern region and consumption centres. Data on transport costs is derived from Indian Railways. Imported coal assumes a price of USD 90/t (plus a 5\% import duty) and that the coal is consumed near the unloading port.

As expected, the cheapest option is the coal-fired plant using domestic coal on-site, despite its low efficiency. A CCGT using the former APM gas (at USD 1.8/MBtu) would nevertheless have come second, but as mentioned earlier, these cheap supplies are not longer available. Coal-fired plant with domestic coal currently remains competitive against imported LNG (Qatar) up to a transport distance of $1300 \mathrm{~km}$. But gas-fired plants using KG-D6 gas, APM gas or more expensive supply sources would remain more expensive than any coal-fired plants (see Figure 4).

21 The latest available freight rates unfortunately date from 2006/07. 
The second approach is to look at the generating costs for new plants. The methodology used is the one applied in our Projected Costs Generating Electricity 2010 Study. ${ }^{22}$ All plants have a 10\% discount rate. Gas-fired plants have a lifetime of 30 years versus 40 years for coal-fired plants. No $\mathrm{CO}_{2}$ costs have been taken into account. All plants use the same price assumptions as for SRMC, except the former APM gas price (at USD 1.8/MBtu) as this will not be available for a plant post-2010. As we look at new plants, the resultant costs appear lower than the SRMC; this is due to better efficiencies of the new power plants.

- The $250 \mathrm{MW}$ gas-fired plants have a PLF of $85 \%$ and a $57 \%$ efficiency. The PLF reflects a situation where supply is available for the plant, and is more optimistic than the current situation where PLF is at $66 \%$

- All new coal-fired plants have a PLF of $85 \%$ and a $46 \%$ efficiency.

Figure 4: SRMC of coal-fired plants versus gas-fired plants

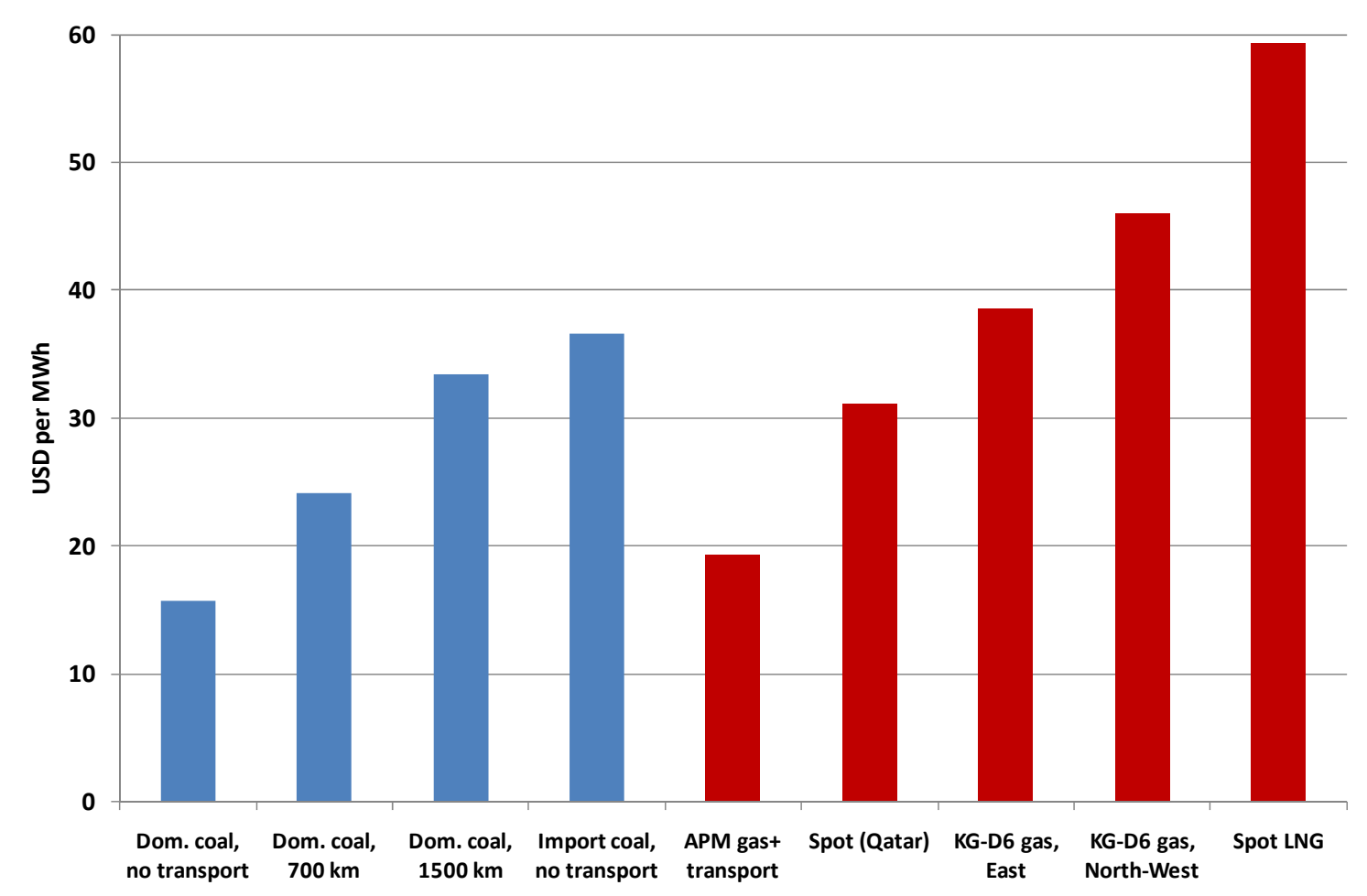

As expected, new coal-fired plants using domestic coal within $700 \mathrm{~km}$ around the mine are more competitive than any gas-fired plant, even using Qatari LNG. Gas-fired plants using contracted LNG, APM gas or KG-D6 gas and located close to these supply sources could be competitive against some domestic coal-fired generation and definitely against coal plants using imported coal. Only when APM or KG-D6 gas has to be transported over long distances do gas-fired plants become less competitive than all coal-fired plants. If the gas price is above USD 6.2/MBtu delivered, then gas-fired plants are less competitive than coal-fired plants for base-load generation.

22 Refurbishment costs have not been taken into account, and decommissioning has been assumed at $5 \%$ of CAPEX. 
Figure 5: Generating costs of coal-fired plants versus gas-fired plants

Page | 42

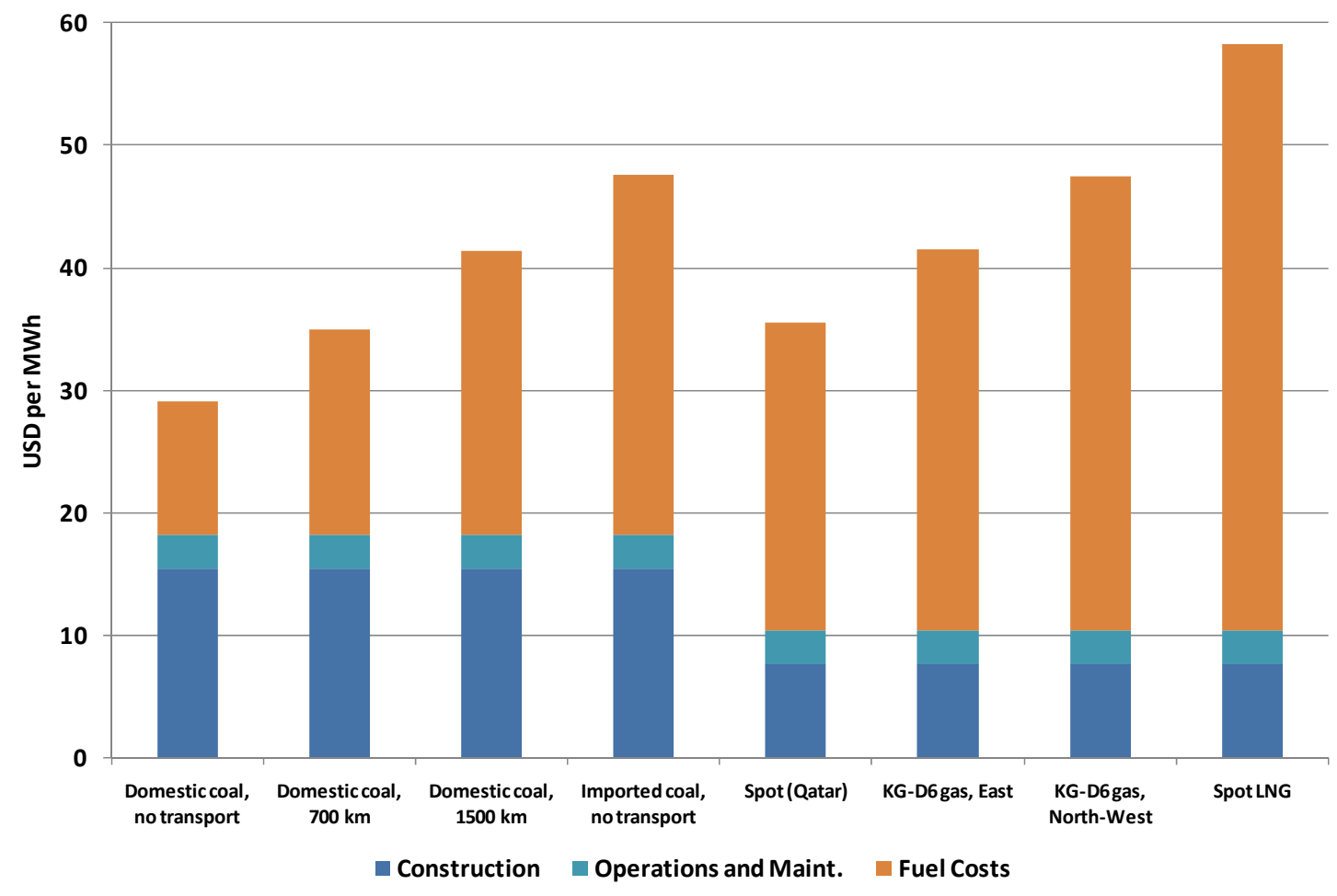

Note: APM gas reflects APM prices before June 2010.

Sources: IEA, Projected Costs Generating Electricity, Standford University, Indian railways, Coal India.

To conclude, coal-fired power has currently a competitive advantage using domestic coal in India, but in some cases depending on the location of the plant, future gas-fired plants could be more competitive. New gas-fired plants using APM or KG-D6 gas could compete against coal plants using imported coal for base-load generation. The role of gas depends on where future coal-fired plants would be located, the evolution of local and imported coal prices, and whether the shortages of coal will continue. If reforms in the coal sector are successful, the role of gas in base load will be more limited. But if insufficient coal supplies are available, gas could be used more widely, even more if gas has become more expensive, while the cost would be passed to end users.

\section{Fertilisers}

The fertiliser industry uses natural gas as a primary feedstock instead of the more expensive naphtha or fuel oil. In 2008/09, gas demand in this sector represented $9 \mathrm{bcm}$, one fifth of total demand, but demand has been very variable over the past five years, mainly constrained by the lack of availability of gas. The sector is key to maintain food self-sufficiency; it has therefore always been heavily subsidised, with subsidies increasing from INR 15879 crore in 2004/05 to INR 75849 crore (USD 16.6 billion) in 2008/09. This policy is therefore very expensive, especially as gas from KG-D6 was more expensive than APM-gas while urea prices to farmers are capped by the government. Over the past year, several fertiliser units have been switching to gas as new supplies from KG-D6 have become available. It can be expected that most fertiliser plants will switch from naphtha and fuel oil to gas in the coming years, as this has been encouraged by the government. It is also more cost effective to use gas instead of expensive naphtha: the Fertilizer Industry Coordination Committee (FICC) reported a 18\% drop in the average cost for urea production in 2009 after KG-D6 gas replaced costlier alternative fuels like naphtha. 
The main unknowns for future gas demand in this sector are the future subsidy policy for the farm gate price of urea and the government's policy on self-sufficiency. Discussions to phase out subsidies for urea production by 2012 are ongoing; the issue will become even more challenging with the recent increase in APM prices. The government's decision to allow more urea to be imported will also be key. There are already JVs in the Middle East, for example in Oman, which produce fertiliser at a much lower price as gas is available at much lower prices (around USD 1/MBtu). But such a decision could face opposition from agricultural lobbies. A future shift to a greater role for imports would dramatically reduce domestic gas consumption and lessen the subsidy burden on the central government.

\section{Industrial gas use}

In 2008/09, industrial gas demand (excluding fertilisers) amounted to $14.5 \mathrm{bcm}$ - around one third of total demand. Petrochemicals and LPG represent half of this demand, while "industrial use" represent only one third. The petrochemical industry faces similar challenges as the fertiliser industry in terms of access to cheap raw material. The growth of this industrial use during 2008/09 has been a remarkable $80 \%$ to $5.9 \mathrm{bcm}$ (see Table 9). Due to the Gas Policy, many industrial customers (apart from LPG and petrochemicals) have no access to cheap gas and have to buy market priced gas from private companies. They need to accept the international prices or use another fuel (like naphtha). As can be seen in Table 10, the industrial sector has the potential to grow by $10 \%$ per year driven by India's strong economic growth. But industrial gas demand is still only a fraction of the potential market, as poor economics due to pricing issues, substitution difficulties for technical reasons, and non-availability caused by the lack of infrastructure together make industrial demand difficult to meet. The major opportunity for growth is in displacing naphtha use where prices exceed USD 10/MBtu.

\section{Retail}

\section{City gas}

The residential sector still uses predominantly biomass, which represents around $80 \%$ of its energy demand. This share is expected to progressively drop due to urbanisation and higher incomes, but biomass will remain the main fuel in rural areas. In the cities, LPG, then electricity and gas are increasingly used for heating and cooking. It is estimated that 286 million people live in cities representing $28 \%$ of the population but this number is expected to increase to 575 million by 2030 (41\% of population) (MoHUPA, 2009). But urban poverty remains high with an estimated 80 million people living in cities and towns having low or no access to more efficient sources of energy. So far, gas has played a limited role in the residential sector and is limited to major cities; this sector therefore represents a small share of total gas demand. Gas use is expected to grow significantly in major cities where expansion of networks in underway or planned, but it will not expand to rural areas. The aim is to have gas distribution in place in all cities with more than 2.5 million inhabitants and then to have cities with a population between 1 and 2.5 million covered by phases. The growth will require enhanced infrastructure development, and a clear regulatory framework to enhance the development of gas distribution in cities. Out of all KG-D6 gas, only $5 \mathrm{Mcm} / \mathrm{d}$ have been allocated to CGD (plus $2 \mathrm{Mcm} / \mathrm{d}$ on an interruptible basis), but not all can be effectively absorbed by the existing infrastructure. 


\section{CNG}

There are an estimated 700000 natural gas vehicles (NGV) in India making India the fifth country after Pakistan, Argentina, Brazil and Iran in terms of NGVs. Although the growth in the number of cars has been impressive over the past decade (there were only 10000 in 2000),

Page | 44 NGVs only represent a small share of total vehicles. There have been two main drivers for NGV programmes in India: improving local air quality and reducing the costs due to oil product prices' subsidies. Air pollution has been a rising concern for Gol; in 2003, MoPNG released its Auto Fuel Policy to address these issues. Although it was recognised that liquid fuels would remain the backbone in the transport sector (with an upgrade of the specifications), the use of NGV and LPG would be encouraged. Over the past decade, CNG programmes were introduced in nearly 30 cities, leading to a steady growth in the number of NGVs (buses, three-wheelers, taxis and small commercial vehicles). The 30 cities are mostly located in Maharashtra and Gujarat, in the North-West of the country. Some individual state governments have taken actions such as tax exemptions, lower interest on loans to support the development of NGVs.

As in the residential sector, the growth of gas use in the transport sector faces three major obstacles: expansion of the gas transport network to the cities; construction of the necessary infrastructure within the city, including refilling stations; and the availability of gas for CNG. 


\section{Conclusion}

India has the potential to become a large gas consumer, even if gas remains a small part of the total primary energy supply. Gas demand is likely to increase above $100 \mathrm{bcm}$ by the next decade. It would provide the benefits of a more environmentally friendly and flexible fuel in a country dominated by coal and biomass. The lack of infrastructure and a flat domestic gas production have constrained gas use so far, in particular in the power generation and the industrial sectors. The start of the Krishna Godavari KG-D6 field in April 2009, which will ultimately double India's gas production up to $60 \mathrm{bcm}$, has already significantly changed the market with consumption increasing by around 16 bcm in 2009/10.

In 2010, the Indian gas market is nevertheless at a crossroads. Despite the dramatic increase of domestic production, substantial issues remain which will have to be solved for the Indian gas market to reach its potential. Four issues have been analysed within this Working Paper: regulation/policy, pricing, supply, and infrastructure.

The issues regarding policy are probably the most important: India needs a clear policy and regulatory framework in order to attract the investments needed in the energy sector, not only to sustain a high economic growth, but also to deal with poverty which leaves millions of people without access to energy. The role and powers of the regulators have to be clearly defined. India has opened up to private and foreign companies and these want regulatory stability with minimum intervention from the state.

The government has reduced the gap between very cheap APM gas and more expensive other supplies. The dual system had indeed proven its shortcomings, which were increasingly visible as APM gas volume and share in total supplies diminished. Keeping low energy prices was not only a disincentive for upstream investment, resulting in losses for PSUs, but also discouraged investments in energy efficiency on the demand side. In the long term, additional LNG supplies are likely to be needed, but would also be more expensive than the current USD 3/MBtu paid for Qatari LNG. If India wants to attract additional LNG in the long term, it will have to increasingly compete in global gas markets at prices potentially higher than the current ones; otherwise LNG supplies will be taken by other Asian markets such as China. Pricing is also key for the demand side due to some sectors' sensitivity to gas prices: gas-fired plants must compete with coal-fired plants which are usually more competitive. However, in some cases gas-fired plants near production sources or import terminals could be more competitive than coal-fired plants, especially those using imported coal or domestic coal shipped over long distances. Gas use for fertiliser production depends on government policy towards dependency on other countries and subsidies, as fertilisers can be produced at a cheaper price in nearby Middle Eastern countries.

Pricing will determine the balancing point between supply and demand. There have been some positive developments in the upstream sector resulting in an increasing participation of JV and private companies and a certain number of discoveries including Krishna Godavari KG-D6, but the NELP is also facing some shortcomings mainly linked to policy and pricing issues. India remains largely under-explored and major efforts have to be made in this respect to develop additional domestic supplies. Although India is also located near significant resources of gas in Turkmenistan and Iran, pipeline interconnections remain a distant prospect. India has been turning to LNG instead and is building new regasification terminals, which will increase the existing capacity by half to around $30 \mathrm{bcm}$. Future supplies in the coming five years will be therefore based on two sources: domestic production and LNG supplies. 
Before domestic production or LNG imports can satisfy market demand, there is a need for infrastructure development not only in terms of new import infrastructure but also in terms of transmission pipelines as production centres progressively shift eastwards. India is a vast country and the transmission network has been developed mostly in the North-West. In 2008, a pipeline was built to link a new production region in the East to the existing network. In order to

Page | 46 further develop the use of gas, it is critical to extend the transmission infrastructure to supply new city distribution networks. In both cases, the regulatory framework, in particular transport tariffs, should give enough incentives for the new infrastructure to be built. 


\section{Acronyms}

ADB Asian Development Bank

AOC Assam Oil Company

APM Administrative price mechanism

BOC Burmah Oil Company

BPCL Bahrat Petroleum Company Limited

CBM Coalbed methane

CGD City Gas Distribution

CNG Compressed natural gas

CTA Capacity tranche agreements

DGH Directorate General for Hydrocarbons

EGoM Empowered Group of Ministers

EWPL East-West pipeline

GAIL Gas Authority of India Limited

GDP Gross domestic product

GGCL Gujarat Gas Company Limited

Gol Government of India

GSPCL Gujarat State Petroleum Corporation Limited

GTA Gas transmission agreements

HVJ Hazira-Vijapiur-Jagdishpur pipeline

IEA International Energy Agency

IGL Indraprastha Gas Limited

INR Indian Rupee

IOC International oil company

IOCL Indian Oil Corporation Limited

IPI Iran-Pakistan-India pipeline

JCC Japanese Crude Cocktail

JV Joint-Venture

LNG Liquefied natural gas

MoPNG Ministry of Petroleum and Natural Gas

NDR National Data Repository

NELP New Exploration Licensing Policy

NGG Natural gas grid

NGV Natural gas vehicle 
NTPC National Thermal Power Corporation

OALP Open Acreage Licensing Policy

OIL Oil India Limited

ONGC Oil and Natural Gas Corporation

PLF Plant load factor

PMT Punna Mukta Tapi (fields)

PNGRB Petroleum and Natural Gas Regulatory Board

PPAC Petroleum Planning \& Analysis Cell

PSC Production sharing contract

PSU Public Service Undertaking

RGTIL Reliance Gas Transportation Infrastructure Limited

RNRL Reliance Natural Resources Limited

SME Small and medium enterprises

TAPI Turkmenistan-Afghanistan-Pakistan-India pipeline

USD US Dollars

WEO World Energy Outlook 


\section{Abbreviations}

Energy

toe tonne of oil equivalent

Mtoe million tonnes of oil equivalent

MBtu million British therman units

Gas

bcm billion cubic meters

$\mathrm{Mcm}$ million cubic meters

tcm trillion cubic meters

tcf trillion cubic feet

$\mathrm{Mcm} / \mathrm{d}$ million cubic meters per day

\section{Electricity}

GW Gigawatt

Other

Crore 10 million (Indian word) 


\section{References}

CEA (Central Electricity Authority) (2008), Annual Report 2007/08, CEA, Ministry of Power, New Delhi.

CEA (2010), Electrical Energy Generation during the month of January 2010 and the period April'09- January 2010, CEA, New Delhi.

CEA, Electrical Energy Generation during the month of February 2010 and the period April'09April 2010, CEA, New Delhi.

Chatterjee, T. K. (2009), Roundtable discussion on gas allocation, NTPC, New Delhi.

Directorate General for Hydrocarbons (2008), Petroleum exploration and production activities Annual Report 2007/08, MoPNG, New Delhi.

IEA (International Energy Agency) (2007), World Energy Outlook, China and India Insights, IEA, Paris.

IEA (2009), World Energy Outlook, IEA, Paris.

IEA (2010a), India's Downstream Petroleum Sector Refined product pricing and refinery investment, IEA, Paris.

IEA (2010b), Natural Gas Vehicles, Working Paper, IEA, Paris.

Jackson, M.P. (2007), The Future of Natural Gas in India: A Study of Major Consuming Sectors, Stanford University, Stanford.

KPMG (2009), The Oil and Gas Sector Overview in India 2009, KPMG, Mumbai.

MoPNG (Ministry of Petroleum and Natural Gas) 2000, Hydrocarbon vision 2025, New Delhi.

MoPNG (2003), Auto Fuel Policy, MoPNG, New Delhi.

MoPNG (2006), Report of the Working Group on Petroleum \& Natural Gas Sector for the XI Plan, MoPNG, New Delhi.

MoPNG (2008), Basic Statistics on Indian Petroleum \& Natural Gas 2007-08, MoPNG, New Delhi.

MoPNG (2009a), Annual Report 2008/09, MoPNG, New Delhi.

MoPNG (2009b), Basic Statistics on Indian Petroleum \& Natural Gas 2008-09, MoPNG, New Delhi.

MoHUPA (Ministry of Housing and Urban Poverty Alleviation) and United Nation Development Programme (2009), Urban poverty report 2009, MoHUPA, New Delhi.

Oil and Natural Gas Corporation (ONGC) (2009), Corporate presentation, August 2010, ONGC, Mumbai.

ONGC (2010), Investors' and Analysts' Meet Annual Results FY'09, ONGC, Mumbai.

Mahajan R. (2008), Indian gas regulatory framework, Ernst \& Young, New Delhi.

Rajpal S.D. (2009), Issues and marketing strategies of natural gas in India, University of Petroleum and Energy Studies, Dehradun.

Shukla, P.R., S. Dhar, D. G. Victor, and M. Jackson (2007), Natural Gas in India: An Assessment of Demand from the electricity sector, Stanford University, Stanford.

Kaushik V. (2008), Outlook for Availability of Feed Stock for Nitrogenous Industry, Kribhco Shyam Fertilizers Limited, Hazira. 


\section{iea}

\section{International Energy Agency}
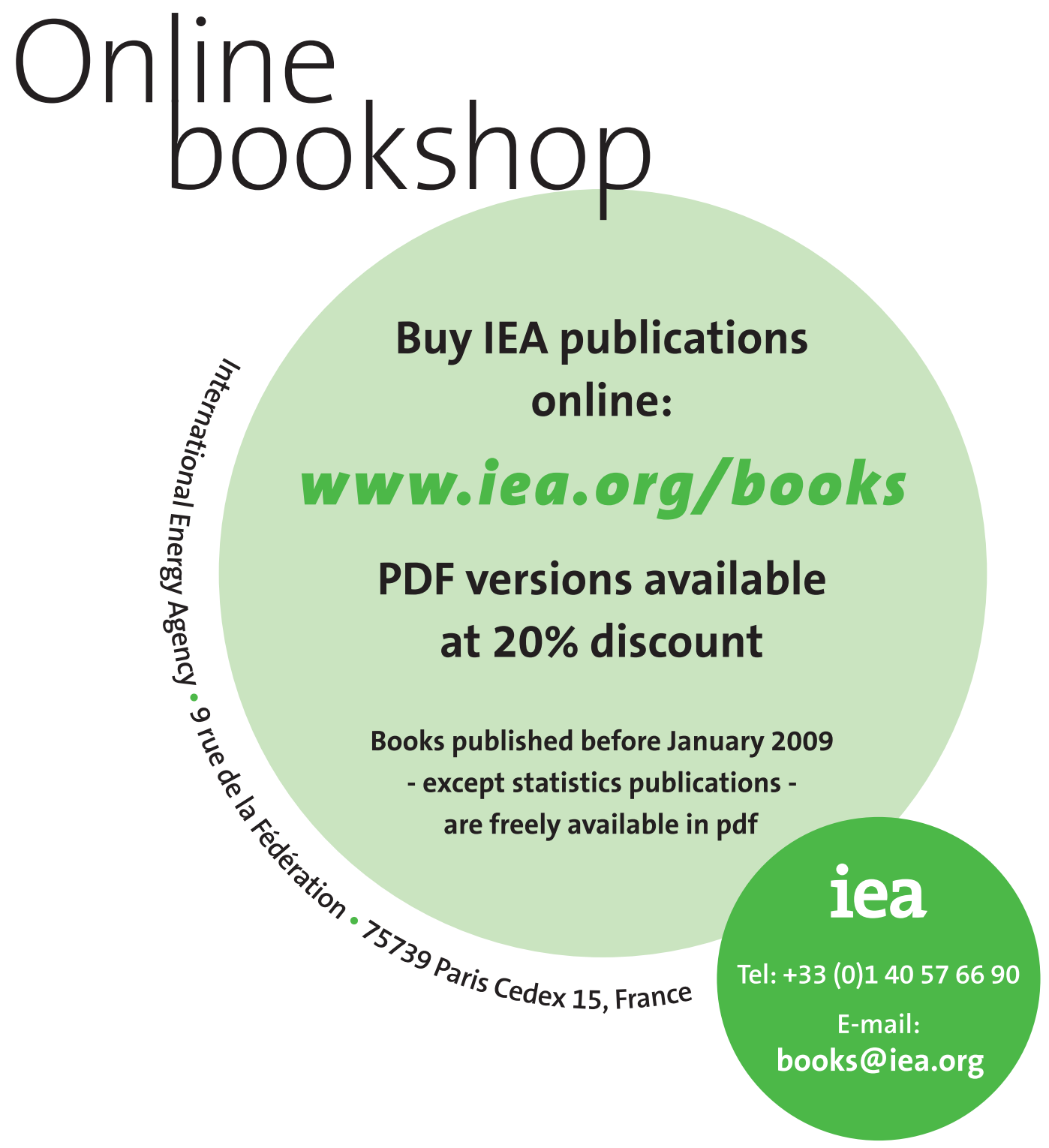


International Energy Agency

9 RUE DE LA FÉdÉRATION 75739 Paris Cedex 15

www.iea.org 